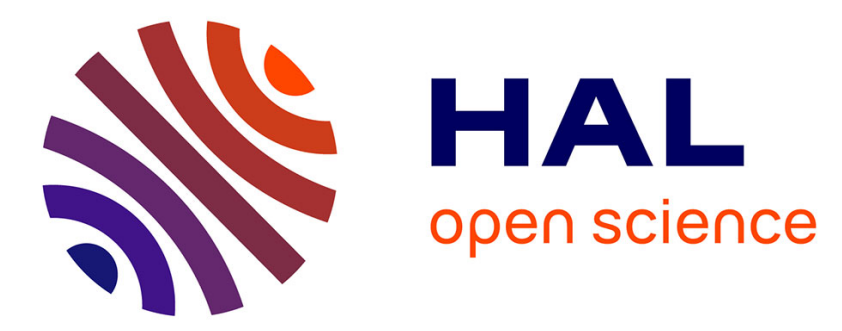

\title{
A comparative analysis of the vestibular apparatus in Epipliopithecus vindobonensis: Phylogenetic implications
}

Alessandro Urciuoli, Clément Zanolli, Amelie Beaudet, Marta Pina, Sergio Almécija, Salvador Moyà-Solà, David M. Alba

\section{To cite this version:}

Alessandro Urciuoli, Clément Zanolli, Amelie Beaudet, Marta Pina, Sergio Almécija, et al.. A comparative analysis of the vestibular apparatus in Epipliopithecus vindobonensis: Phylogenetic implications. Journal of Human Evolution, 2021, 10.1016/j.jhevol.2020.102930 . hal-03103052

\section{HAL Id: hal-03103052 https://hal.science/hal-03103052}

Submitted on 7 Jan 2021

HAL is a multi-disciplinary open access archive for the deposit and dissemination of scientific research documents, whether they are published or not. The documents may come from teaching and research institutions in France or abroad, or from public or private research centers.
L'archive ouverte pluridisciplinaire HAL, est destinée au dépôt et à la diffusion de documents scientifiques de niveau recherche, publiés ou non, émanant des établissements d'enseignement et de recherche français ou étrangers, des laboratoires publics ou privés. 
1 A comparative analysis of the vestibular apparatus in Epipliopithecus vindobonensis:

2 Phylogenetic implications

Alessandro Urciuoli ${ }^{a,{ }^{*}}$, Clément Zanolli ${ }^{b}$, Amélie Beaudet a, ${ }^{c, d, a}$, Marta Pina ${ }^{a, e}$, Sergio Almécija $^{\mathrm{f}, \mathrm{g}, \mathrm{a}}$, Salvador Moyà-Solà $^{\mathrm{a}, \mathrm{h}, \mathrm{i}}$, David M. Alba ${ }^{\mathrm{a},{ }^{*}}$

a Institut Català de Paleontologia Miquel Crusafont, Universitat Autònoma de Barcelona,

Edifici ICTA-ICP, c/ Columnes s/n, Campus de la UAB, 08193 Cerdanyola del Vallès,

Barcelona, Spain

${ }^{\mathrm{b}}$ Univ. Bordeaux, CNRS, MCC, PACEA, UMR 5199, F-33600 Pessac, France

${ }^{c}$ School of Geography, Archaeology and Environmental Studies, University of the

Witwatersrand, Private Bag 3, Johannesburg, WITS 2050, South Africa

d Department of Anatomy, University of Pretoria, PO Box 2034, Pretoria, 0001, South

Africa

e School of Earth and Environmental Sciences, Faculty of Science and Engineering,

University of Manchester, 176 Oxford Road, Manchester M13 9PL, UK

${ }^{\mathrm{f}}$ Division of Anthropology, American Museum of Natural History, Central Park West at $79^{\text {th }}$

Street, New York, NY 10024, USA

${ }^{g}$ New York Consortium in Evolutionary Primatology, New York, NY, USA

h Institució Catalana de Recerca i Estudis Avançats (ICREA), Passeig de Lluís Companys 23, 08010 Barcelona, Spain

' Unitat d’Antropologia (Departament de Biologia Animal, Biologia Vegetal i Ecologia),

Universitat Autònoma de Barcelona, Campus de la UAB s/n, 08193 Cerdanyola del Vallès, Barcelona, Spain 
E-mail address: alessandro.urciuoli@icp.cat (A. Urciuoli); david.alba@icp.cat (D.M. Alba).

${ }^{3}$ Department of Archaeology, University of Cambridge, Fitzwilliam St, Cambridge CB2 $1 \mathrm{QH}$, UK.

\section{Abstract}

Pliopithecoids are an extinct group of catarrhine primates from the Miocene of Eurasia. More than fifty years ago, they were linked to hylobatids due to some morphological similarities, but most subsequent studies have supported a stem catarrhine status, due to the retention of multiple plesiomorphic features (e.g., the ectotympanic morphology) relative to crown catarrhines. More recently, some morphological similarities to hominoids have been noted, raising the question of whether they could be stem members of this clade. To re-evaluate these competing hypotheses, we examine the morphology of the semicircular canals of the bony labyrinth of the middle Miocene pliopithecid Epipliopithecus vindobonensis. The semicircular canals are suitable to test between these hypotheses because: (1) they have been shown to embed strong phylogenetic signal and reliably discriminate among major clades; (2) several potential hominoid synapomorphies have been identified previously in the semicircular canals; and (3) semicircular canal morphology has not been previously described for any pliopithecoid. We use a deformation-based (landmark-free) three-dimensional geometric morphometric approach to compare Epipliopithecus with a broad primate sample of extant and extinct anthropoids. We quantify similarities in semicircular canal morphology using multivariate analyses, reconstruct ancestral morphotypes by means of a phylomorphospace approach, and identify catarrhine and hominoid synapomorphies based on discrete characters. Epipliopithecus semicircular canal morphology most closely resembles that of platyrrhines and Aegyptopithecus due to the retention of multiple anthropoid symplesiomorphies. However, Epipliopithecus is most parsimoniously interpreted as a stem catarrhine more 
derived than Aegyptopithecus due to the possession of a crown catarrhine synapomorphy (i.e., the rounded anterior canal), combined with the lack of other catarrhine and any hominoid synapomorphies. Some similarities with hylobatids and atelids are interpreted as homoplasies likely related to positional behavior. The semicircular canal morphology of Epipliopithecus thus supports the common view that pliopithecoids are stem catarrhines.

Keywords: Pliopithecidae; Catarrhini; Miocene; Inner ear; Phylogeny; Geometric morphometrics

\section{Introduction}

\subsection{The phylogenetic position of pliopithecoids}

Pliopithecoids are an extinct superfamily of catarrhine primates, recorded in Eurasia from the early to the late Miocene (Andrews et al., 1996; Begun, 2002, 2017; Harrison, 2005, 2013). Their first occurrence, in the early Miocene of China ( 18-17 Ma; Harrison and Gu, 1999; Begun, 2002; Harrison, 2013), slightly predates the oldest record of largebodied apes in Eurasia (Heizmann and Begun, 2001; Casanovas-Vilar et al., 2011). In the absence of older (earliest Miocene) catarrhines in that continent, pliopithecoids are assumed to have an African origin (Harrison, 1987, 2013; Begun, 2017). Like apes, pliopithecoid ancestors probably dispersed into Eurasia before the Langhian transgression, which was possible due to the lowered sea level and tectonic events that led to the closure of the Tethys Seaway and the establishment of an intermittent terrestrial corridor beginning at $19 \mathrm{Ma}$ (Harzhauser et al., 2007; Harrison, 2013).

Decades ago, pliopithecoids were considered to be phylogenetically related to hylobatids due to some superficial resemblances in cranial morphology as well as body size and proportions (e.g., Hürzeler, 1954; Zapfe, 1958, 1960, 1961; Simons and Fleagle, 1973). Currently, they are generally considered a clade of stem catarrhines-as supported 
by the retention of several cranial and postcranial features that are plesiomorphic compared to the crown members of the group (Andrews, 1975; Ciochon and Corruccini, 1977; Fleagle, 1984; Harrison, 1987, 2005, 2013; Andrews et al., 1996; Begun, 2002 , 2017). The divergence of pliopithecoids before the split of crown catarrhines is further supported by most recent cladistic analyses (Zalmout et al., 2010; Stevens et al., 2013; Nengo et al., 2017; Gilbert et al., 2020), implying a long ghost lineage of ca. 12-14 Myr for pliopithecoids (Begun, 2017). The exception is the cladistic analysis by Alba et al. (2015), which recovered pliopithecoids as a clade of stem hominoids-thereby eliminating the need to hypothesize a long gap in the pliopithecoid fossil record. Most recently, Almécija et al. (2019) further documented similarities in femoral morphology between pliopithecoids (Epipliopithecus) and extant hominoids, thereby casting additional doubts on the status of pliopithecoids as stem catarrhines. Further uncertainty in this regard stems from the fact that no tail vertebrae are known from pliopithecoids (Begun, 2017). Based on sacral morphology, Zapfe $(1958,1961)$ argued that no external tail would have been present, as in hominoids; although this has subsequently been rebutted (Ankel, 1965; Russo, 2016), available evidence in this regard remains uncertain.

There are multiple genera of pliopithecids (Harrison and Gu, 1999; Moyà-Solà et al., 2001; Begun, 2002, 2017; Harrison, 2005, 2013; Alba et al., 2010; Alba and Moyà-Solà, 2012; Alba and Berning, 2013; Sankhyan et al., 2017; Harrison et al., 2020), which, following Harrison et al. (2020), we provisionally group into four different families: dionysopithecids (Dionysopithecus and Platodontopithecus), krishnapithecids (Krishnapithecus), pliopithecids (Pliopithecus and Epipliopithecus), and crouzeliids (Plesiopliopithecus, Barberapithecus, Anapithecus, Egarapithecus, and Laccopithecus). However, it is noteworthy that the treatment of these genera at the family rank, and even the placing of some genera in one or another group, differs among authors (e.g., compare Alba and Moyà-Solà, 2012 with Begun, 2017). Such disagreements largely stem from the 
105 fact that the internal phylogeny of pliopithecoids is still unclear and that their affinities with 106 fossil catarrhines from Africa remain uncertain (e.g., Harrison, 2013).

107

\subsection{Evidence from Epipliopithecus}

Deciphering the phylogenetic relationships of most pliopithecoids is hampered by the fact that they are mostly known by fragmentary dentognathic remains, with the exception of Epipliopithecus vindobonensis, whose craniodental and postcranial morphology is well documented by several skeletons from the middle Miocene (MN6, 14.85-13.45 Ma1) karstic infillings of Devínska Nová Ves, Slovakia (Zapfe, 1958, 1961; Andrews et al., 1996; Begun, 2002; Harrison, 2013). Epipliopithecus was originally established as a subgenus of Pliopithecus by Zapfe and Hürzeler (1957), being subsequently considered a junior subjective synonym of the latter (e.g., Andrews et al., 1996; Harrison and Gu, 1999; Moyà-Solà et al., 2001; Harrison, 2005, 2013; Alba et al., 2010) or a distinct genus (e.g., Begun, 2002; Alba and Moyà-Solà, 2012; Arias-Martorell et al., 2015; Alba et al., 2015; this study). From a locomotor viewpoint, E. vindobonensis has been variously depicted as an arboreal or semiterrestrial generalized quadruped with varying degrees of climbing and suspensory abilities (see discussion in Arias-Martorell et al., 2015). From a phylogenetic perspective, its purported stem catarrhine status has been supported by features such as the short and only partially enclosed ectotympanic, the presence of entepicondylar foramen in the distal humerus, and single hinge-like carpometacarpal joint in the thumb (Zapfe, 1961; Szalay and Delson, 1979; Harrison, 1987, 2005; Andrews et al., 1996; Begun, 2002, 2017).

\footnotetext{
${ }^{1}$ Age uncertainly based on the boundaries recognized for MN6 (van der Meulen et al., 2011).
} 
The external morphology of the petrosal bone of E. vindobonensis (Zapfe, 1961;

Szalay, 1975; Fricano, 2018) has been of utmost significance in the discussion of its phylogenetic affinities, given that the presence of a tubular ectotympanic is considered synapomorphic of crown catarrhines (e.g., Szalay, 1975; Szalay and Delson, 1979; Harrison, 1987, 2005; Andrews et al., 1996; Begun, 2002; Zalmout et al., 2010; Alba et al., 2015; Nengo et al., 2017). The possibility remains that such ossification took place to some extent independently in cercopithecoids, hominoids and/or other anthropoids such as pliopithecoids (Begun, 2002, 2017; Alba et al., 2015). However, other features of Epipliopithecus also appear plesiomorphic as compared to crown catarrhines and show no particular similarities with hominoids, namely: the large postglenoid process separated from the acoustic meatus, as in platyrrhines (Zapfe, 1961); the lack of ossification in the tentorium cerebelli (unlike in most platyrrhines and stem anthropoids, but similar to Aegyptopithecus and crown catarrhines; Kay et al., 2009a); and the deep subarcuate fossa (Zapfe, 1961), as in platyrrhines and most anthropoids except hominids (Gannon et al., 1988; Kunimatsu et al., 2019). In contrast, the inner ear morphology of Epipliopithecus has not been described and therefore its potential phylogenetic implications remain unexplored.

\subsection{The bony labyrinth of the inner ear}

Among the inner cavities of the petrosal, the bony labyrinth of the inner ear is constituted by the semicircular canals (SCs) and the vestibule (which together host the soft-tissue structures linked with the sense of balance) plus the cochlea. Semicircular canal size (e.g., Spoor et al., 2007; Silcox et al., 2009; Ryan et al., 2012; Grohé et al., 2018) and orientation (David et al., 2010; Malinzak et al., 2012; Berlin et al., 2013; Perier et al., 2016; Gonzales et al., 2019) have been frequently used for inferring agility, while the shape of the canals as a whole has tentatively been linked to positional behavior (Le 
Maître et al., 2017). At the same time, recent studies have demonstrated that the SCs bear strong phylogenetic signal among anthropoids (Lebrun, 2010, 2012; Urciuoli et al., 2019, 2020; del Rio et al., 2020; Morimoto et al., 2020) and other mammals (e.g., Grohé et al., 2015; Mennecart et al., 2016, 2017; Costeur et al., 2018).

Although adaptively relevant characters may constitute synapomorphies of particular clades, arguably their relationship with function makes them potentially more prone to homoplasy. However, the correlation between SC morphology and positional behavior has recently been questioned by some studies (i.e., Rae et al., 2016; del Río et al., 2020; Morimoto, et al., 2020), and SC shape variation has been shown to largely follow the expectations of a Brownian motion mode of evolution in both platyrrhines (del Río et al., 2020) and catarrhines (Urciuoli et al., 2020). These results are in accordance with those obtained for the bony labyrinth as a whole, showing that its morphology reflects phylogenetic relatedness as inferred from molecular data (Lebrun et al., 2010; Ekdale, 2013; Macrini, et al., 2013; Billet et al., 2015). Cumulatively, this evidence suggests that bony labyrinth morphology is phylogenetically informative among mammals (Mennecart et al., 2017) and may thus potentially illuminate the phylogenetic relationships of extinct primates. Following Mennecart and Costeur (2016), who suggested that inner ear structures might be highly informative for large cladistics analyses, Urciuoli et al. (2020) explored catarrhine SC shape variation among catarrhines and proposed several potential synapomorphies for crown hominoids.

Here we test between two different phylogenetic hypotheses for Epipliopithecus, one hypothesis being that Epipliopithecus is a stem catarrhine, the other hypothesis that Epipliopithecus is a hominoid, based on the information provided by the shape of the SCs and vestibule. This morphology is described here for the first time using a threedimensional geometric morphometric (3DGM) approach applied to a broad sample of extant and fossil anthropoids (Urciuoli et al., 2020). We refrained from analyzing the entire 
bony labyrinth (i.e., including also the cochlea) because its potential for phylogenetic reconstruction among primates is currently unclear. A recent analysis in platyrrhines suggested that cochlear shape departs from a Brownian motion mode of evolution (Blomberg's $\mathrm{K}<1$; del Río et al., 2020), thus potentially reflecting a greater influence of function (and likely homoplasy due to similar selection pressures) than is the case for the SCs and vestibule. This is in agreement with previous studies linking several macroscopic cochlear features to hearing capabilities (e.g., Manoussaki et al., 2006; Kirk and GosselinIldari, 2009; Coleman and Colbert, 2010). More detailed morphometric analyses of this structure among anthropoids is thus required to determine whether cochlear morphology can be meaningfully used to decipher the phylogenetic relationships of extinct catarrhines such as Epipliopithecus.

\section{Materials and methods}

\subsection{Described material}

We inspected three petrosals of $E$. vindobonensis belonging to two individuals from Devínska Nová Ves, Slovakia (Zapfe, 1960, 1961): NMB OE 303a, b (individual III), left (a) and right (b), housed in the Naturhistorisches Museum of Basel, Switzerland ${ }^{2}$; and NHMW 1970/1397/0003 (individual II), right, housed in the Naturhistorisches Museum of Wien, Austria.

\subsection{Comparative sample}

The comparative sample includes $\mu \mathrm{CT}$ scans of 162 dried crania and temporal bones belonging to 31 extant anthropoid species (see Supplementary Online Material [SOM] Table S1 for the sample size of the extant species), plus five fossil anthropoids

\footnotetext{
${ }^{2}$ Morimoto et al. (2020) included the bony labyrinth of NMB OE 303a in their comparative study but did not depict or specifically describe its morphology.
} 
203 (SOM Table S2): the stem anthropoid Parapithecus (Bush et al., 2004), the stem

catarrhine Aegyptopithecus (Simons et al., 2007), the stem platyrrhines Dolichocebus (Kay et al., 2009b) and Homunculus (Fulwood et al., 2016), and the hominoid Oreopithecus (Rook et al., 2004).

\subsection{Sample preparation}

NMB OE 303 was scanned with a Phoenix Nanotom ${ }^{\circledR}$, GE at the Biomaterials Science Centre of the University of Basel (Switzerland) obtaining a voxel size of $25 \mu \mathrm{m}$. NHMW 1970/1397/0003 was scanned at the Vienna $\mu$ CT-Lab using a Viscom X8060 (Viscom XT9190-THP X-ray tube) obtaining a voxel size of $22 \mu \mathrm{m}$. The canals and vestibule of NMB OE 303a, b were filled with air, while in NHMW 1970/1397/0003 they were partially filled with sediment. In both cases we segmented the SCs and vestibule cavities using the 'watershed' tool of Avizo v. 9.0.1 (FEI Visualization Sciences Group, Houston), with additional manual corrections for NHMW 1970/1397/0003. The 3D surfaces of NMB OE 303b and NHMW 1970/1397/0003 were mirrored for comparison. The 3D meshes of the two individuals are available from MorphoSource (see Table 1).

The $\mu \mathrm{CT}$ scans of most extant comparative species and of fossil anthropoids were accessed from MorphoSource.org digital repository (https://www.morphosource.org) with the exception of Oreopithecus bambolii petrosal, which was kindly provided by Lorenzo Rook (see SOM Table S2 for voxel sizes). Further details about the $\mu \mathrm{CT}$ scans of the extant comparative sample (voxel sizes, exact source, DOI, etc.) can be found in Urciuoli et al. (2020: Supplementary File 1). The slice stacks of these crania were processed using Avizo v. 9.0.1. and the left bony labyrinth was segmented using the semiautomatic 'watershed' tool of Avizo (with additional manual corrections in the case of partially filled canals found in the fossil specimens) and digitally extracted; when the left bony labyrinth was unavailable, the right one was mirrored. As in Urciuoli et al. (2020), the SCs and the 
vestibule were separated from the cochlea by cutting the generated 3D meshes immediately inferior to the saccule and the oval window, using landmarks placed along the maximum curvature of the junction between the vestibule and the cochlea as reference for the cutting plane (Fig. 1). The resulting holes were filled with a flat surface using Geomagic Studio v. 2014.3.0 (3D Systems, Rock Hill, USA). Prior to the 3DGM analysis, the surfaces were first roughly prealigned by manually superimposing the meshes to ensure biological correspondence. Subsequently, the alignment was automatically refined using the Avizo module 'Align Surface' with the 'rigid + uniform' option. Similar to Procrustes superimposition, this module minimizes the distances between the faces of each surface by scaling, translating and rotating the analyzed meshes. The phylogenetic relationships of the extinct taxa included in the analyses, relative to extant anthropoids, are summarized in Figure 2.

\subsection{Shape analysis}

Differences in vestibule and SC shape were evaluated using a landmark-free 3DGM technique based on deformation, which relies on the geometrical correspondence of continuous surfaces and computes the magnitude and direction of deformation of the analyzed meshes from a group-average template (Glaunès and Joshi, 2006; Durrleman et al., 2012a, b; Dumoncel et al., 2014; Beaudet et al., 2016; Urciuoli et al., 2020). The deformations are mathematically modeled to obtain a one-to-one correspondence of the 3D space using the open-source software Deformetrica 4 (Bône et al., 2018). This technique yields results similar to landmark-based 3DGM methods while more easily tracking changes in volume (Urciuoli et al., 2020), and is less prone to biases introduced by the design of landmarking protocols, caused by the inherent difficulty to adequately capture complex 3D shapes based on a reduced number of homologous landmarks. 
Due to the high computational power required, the sets of vectors, representing the

255

flow of deformations from the initial position of the control points on the template to the target shape, were computed in the Barcelona Supercomputing Center (BSC) using the MinoTauro cluster (https://www.bsc.es/marenostrum/minotauro). To identify major patterns of shape variation across the sample, the resulting sets of vectors were inspected using between-group principal component analysis (bgPCA; Mitteroecker and Bookstein, 2011), using major clades (platyrrhines, cercopithecoids, hylobatids, and hominids) as the grouping factor (Urciuoli et al., 2020). To address recent concerns about the use of bgPCA based on highly multivariate data sets, such as those generated by 3DGM, and to rule out the presence of spurious groupings in our results (Bookstein, 2019; Cardini, et al., 2019), we computed cross-validated bgPCA scores. These were obtained by iteratively repeating the bgPCA on a subset of the sample. The cross-validated bgPCA scores were then compared to those obtained with standard bgPCA (Cardini and Polly, 2020). The affinities of fossil specimens with the groups defined a priori in the bgPCA were evaluated using the 'typprobClass' function of the Morpho package v. 2.7 (Schlager, 2017) in R v. 3.6.1 (R Core Team, 2019). This function computes posterior probabilities of group membership based on the Mahalanobis distances between the bgPC scores of fossil specimens and group centroids. Null hypotheses of group membership were rejected at $p<0.05$.

Similarities among anthropoid species were also evaluated by running a cluster analysis (Ward's method) on the Mahalanobis distances between pairs of bgPCA species centroid scores using the 'ward.D2' method of the 'hclust' function of the 'stats' package in R. The cophenetic correlation coefficient, which allows one to evaluate how faithfully the obtained dendrogram preserves the pairwise distances between the original unmodeled datapoints, was calculated using the same package.

In addition, we inspected the volumetric proportions of Epipliopithecus and the remaining fossil taxa included in the analysis, and determined the correlation between log- 
transformed cube root canal volume (In VolSC, mm) and log-transformed canal length (In $\mathrm{L}, \mathrm{mm}$ ) by means of ordinary least-squares regression. Given that previous analyses identified an allometric grade shift between hominids and nonhominid anthropoids (Urciuoli et al., 2020), separate regression lines were computed for hominids and nonhominid anthropoid taxa using the 'stats' package in R.

\subsection{Phylomorphospace, ancestral state estimation, and phylogenetic signal}

To intuitively visualize the direction and magnitude of evolutionary change we relied on a phylomorphospace approach (Sidlauskas, 2008), by which a phylogenetic tree is projected onto the tangent space defined by the bgPCA of our shape data. Ancestral states for the internal nodes are estimated using a maximum likelihood method for continuous characters via the 'fastAnc' function of the 'phytools' version $0.6-60$ package for $\mathrm{R}$ (Revell, 2012), while the tips of the tree branches correspond to the centroid scores for the included taxa. We repeated the analyses using two composite phylogenetic trees, one with Epipliopithecus as a stem catarrhine and the other with this taxon as a stem hominoid (Figs. 2 and 3). For extant taxa we relied on a Bayesian phylogenetic analysis of eleven mitochondrial and six autosomal genes downloaded from the 10kTrees Website $\mathrm{v}$. 3 (Arnold et al., 2010). Extinct species were added based on their phylogenetic position, their divergence being arbitrarily placed $1 \mathrm{Myr}$ before the estimated divergence age of the next derived node, and tip ages based on their chronostratigraphic age. We used the following tip age estimates: Epipliopithecus $14.15 \mathrm{Ma}$ (mean of 14.85 and $13.45 \mathrm{Ma}$, the maximum-minimum age range for MN6 in central Europe according to van der Meulen et al., 2011); Aegyptopithecus and Parapithecus, $29.85 \mathrm{Ma}$ (mean of 30.2 and $29.5 \mathrm{Ma}$, based on the revised age range of the fauna of quarries I and M of the Jebel Qatrani Formation of the Fayum depression by Seiffert, 2006); Dolichocebus, $20.5 \mathrm{Ma}$ (mean of 21.0 and 20.0 Ma age provided by Kay, 2015); Homunculus, 17.2 Ma (mean of 17.9 and 
16.5 Ma age provided by Kay, 2015); and Oreopithecus $6.75 \mathrm{Ma}$ (mean of 7.0 and $6.5 \mathrm{Ma}$ for the last occurrence according to Rook et al., 2000).

The phylogenetic signal embedded in the shape data was measured using Pagel's $\lambda$ (Pagel, 1999) and Blomberg's K (Blomberg et al., 2003), together with the multivariate version of Blomberg's $K$ ( $K_{\text {mult }}$; Adams, 2014). Pagel's $\lambda$ and Blomberg's $K$ were computed using the 'phylosig' function of the 'phytools' package in $R$, while $K_{\text {mult }}$ was computed with the 'physignal' function of the 'geomorph' package v. 3.1.0 in R (Adams et al., 2019). These metrics were computed based on extant taxa only (Arnold et al., 2010).

Ancestral node morphologies were computed from the bgPC scores for the last common ancestors (LCAs) estimated by means of maximum likelihood, which were rotated and translated from the morphospace back into the deformation field space, generating a set of momentum vectors that were used in Deformetrica 4 to warp the template surface into the target LCA morphology. Volumetric proportions for the LCAs were computed based on the rescaled 3D models obtained from the phylomorphospace approach; the scaling factor for each LCA was estimated using the 'anc.ML' function of the R package 'phytools'. Morphological similarities between Epipliopithecus and the LCA centroids were assessed by means Euclidean distances between the Epipliopithecus centroid and the LCA bgPC scores, weighted on the basis of the percentage of variance explained by each bgPC and computed using the 'distances' function of the 'distances' package version 0.1 .8 in $\mathrm{R}$ (Savje, 2019).

The two phylogenetic hypotheses for Epipliopithecus depicted in Figure 3 were assessed further based on the coding of seven discrete characters that were deemed of phylogenetic significance based on shape comparisons and analyses. The resulting character-taxon matrix was analyzed for character congruence against a fixed topology consistent with the phylogenetic hypotheses depicted in Figure 3. For both cladograms, three indices customarily employed in cladistics (Farris, 1989) were computed in PAUP* V. 
4.0a168 for Mac (Swofford, 2003) to assess the most parsimonious hypothesis: the consistency index $(\mathrm{Cl})$, the retention index $(\mathrm{RI})$, and the rescaled consistency index $(\mathrm{RC})$.

\section{Results}

\subsection{Description and comparisons}

The three bony labyrinths of $E$. vindobonensis are well preserved-except for the lateral canal of NMB OE 303b, which shows a small fracture in the bony encasing-and are not affected by diagenetic deformation, thereby permitting a straightforward extraction of the 3D surfaces of the vestibular apparatus bony labyrinth (Fig. 4a-c). Overall, the canals are fairly slender, as in platyrrhines and cercopithecins, falling within their variability as shown by a bivariate plot of SC volume vs. length (Fig. 5; Table 2; SOM Table S3). The bony vestibule is large, albeit less so than in hominids. The anterior and posterior canals are larger than the lateral canal, as in platyrrhines (Fig. 4e-i) and modern humans (Fig. $4 u)$.

The E. vindobonensis common crus (CC) is long, as in extant platyrrhines (Fig. 4gi) and in Dolichocebus (Fig. 4e), but unlike in most catarrhines. The trajectories of the anterior and posterior canal form a right angle when merging at the CC apex. Despite some similarities, the morphology of Epipliopithecus is clearly distinguishable from that of Dolichocebus and Parapithecus (Fig. 4d), as the CC is not posteromedially inclined and the anterior canal connection is placed more laterally.

The anterior canal of E. vindobonensis is slightly wider than tall (as in Hoolock; Fig. $4 q$ ), yet clearly rounded and lacking the vertical compression characteristic of extant hominoids (Fig. 4o-u), the anterosuperior elongation typical of hylobatids and Pongo (Fig. 40-r; Urciuoli et al., 2020), and the extreme superior projection found in Ateles (Fig. 4g).

The anterior canal of Epipliopithecus further differs from that of the stem anthropoid Parapithecus (Fig. 4d), the stem platyrrhine Dolichocebus (Fig. 4e), and the stem 
catarrhine Aegyptopithecus (Fig. 4j), characterized by an almost triangular morphology (albeit less so in the last genus). The superiormost portion of the anterior canal bends medially, causing a moderate torsion of the canal trajectory. This morphology is also found in the stem platyrrhine Homunculus (Fig. 4f) and, to a lesser extent, Chlorocebus (Fig. 4l) and Dolichocebus (Fig. 4e), while in most cercopithecoids it is much more bent (e.g., Macaca; Fig. 4m). A sinuous trajectory of the anterior canal, although with a different morphology, is also displayed by other taxa (e.g., Cebus; Fig. 4i) and thus is not very informative from a phylogenetic viewpoint. Despite the aforementioned similarities, Epipliopithecus differs from the stem platyrrhines Homunculus (Fig. 4f) and Dolichocebus (Fig. 4e), from most extant platyrrhines (particularly Ateles; Fig. 4g), and from the stem catarrhine Aegyptopithecus (Fig. 4j), in displaying a much less mediolaterally compressed anterior canal.

The posterior canal of Epipliopithecus is slightly taller than wide, similar to that of Alouatta (Fig. 4h) and Symphalangus (Fig. 4p), but differs from the latter by displaying a less arched connection with the CC. The orientation of the posterior canal relative to the plane defined by the anterior canal is different in the two individuals of Epipliopithecus: it forms an obtuse angle in NHMW 1970/1397/0003 (resembling the hylobatid condition), but forms a right angle in NMB OE 303 (as in other anthropoids; SOM Fig. S2).

The lateral canal is rounded and smaller than the other canals (more so in NMB OE 303), as in stem platyrrhines (Fig. 4e, f) and the stem catarrhine Aegyptopithecus (Fig. 4j), although in Epipliopithecus this canal is not strongly compressed mediolaterally as in the latter taxon (Fig. 4j). The trajectory of the ampullary portion of the lateral canal slightly bends superiorly (more so in NMB OE 303; Fig. 4b, c), while the insertion of its slender part is located anteriorly to the base of the CC (particularly in NHMW 1970/1397/0003; Fig. 4a), so that-as in extant hominoids but unlike cercopithecoids-the lateral canal does not intersect the plane defined by the posterior canal. The lateral canal also shows a wave-like 
shape, with its lateral-most tip pointing downwards, superficially resembling some individuals of Pongo (Fig. 4r), while differing from the morphology of Trachypithecus (Fig. 4k) and Macaca (Fig. 4m), where the canal bends inferiorly right before the ampullary portion.

\subsection{Shape analysis}

The bgPCA discriminates major anthropoid clades with just minimal overlap when the three axes are considered simultaneously (Fig. 6), thus closely resembling the previous results by Urciuoli et al. (2020) despite the increased number of platyrrhine taxa included here. The bgPCA results reported in Figure 6 closely resemble those derived using a cross-validated bgPCA (SOM Fig. S1), indicating that group separation is not spurious (Cardini and Polly, 2020).

The first principal component (bgPC1, which explains $59 \%$ of the variance) mainly reflects differences in volumetric proportions among the SCs and the volume they occupy relative to that of the bony vestibule, separating hominids (stout canals; quite negative scores) from both cercopithecoids and hylobatids (slender canals; positive to slightly negative scores), while platyrrhines (including stem taxa), the stem anthropoid Parapithecus, the stem catarrhine Aegyptopithecus, the stem hominoid Oreopithecus, and Epipliopithecus occupy an intermediate position in the morphospace. In particular, the two Epipliopithecus individuals, due to their fairly slender canals (Fig.4a-C), display similar intermediate scores along this axis, overlapping extensively with both extant and extinct platyrrhines in the overlap zone of cercopithecoids and hominoids (Fig. 6a, c).

In turn, bgPC2 (which explains $30 \%$ of the variance) accounts for differences in the size and shape of the anterior and posterior canals (Fig. 6a, d), in the position of the lateral canal ampullary insertion on the vestibule, and in CC length, separating most platyrrhines (positive scores) from catarrhines (moderately positive to negative scores). In particular, 
platyrrhines possess large and very superiorly elongated canals in the portion close to the

411 CC apex, as well as a flat lateral canal, which also connects more inferiorly on the vestibule with its ampullary portion. Catarrhines are more variable in these features, showing rounded to vertically compressed anterior and posterior canals, a shorter CC, and a variably sinuous lateral canal with its ampullary portion connecting more superiorly. Epipliopithecus displays moderately positive scores, falling within the range of several extant platyrrhines (Aotus, Alouatta, Callithrix and Callicebus), due to their large anterior and posterior canals, coupled with a long CC and a small lateral canal. Both the stem platyrrhines and Oreopithecus show similar moderately positive scores, while Aegyptopithecus and Parapithecus show markedly positive values due to their superiorly elongated vertical canals (Fig. 6a).

Finally, bgPC3 (which explains $11 \%$ of the variance) is driven by the position of the lateral canal relative to the posterior one, by the size and orientation of the posterior canal, as well as the shape of the anterior canal and CC thickness (Fig. 6b, e), separating hylobatids (most positive values) from most extant and fossil anthropoids (intermediate to negative scores). Hylobatids have a much larger gap between the lateral and posterior canals than other anthropoids except some modern humans, and their posterior canal is also smaller than, and forms an obtuse angle with, the large and anteriorly-protruding anterior canal. In contrast, in most cercopithecoids, Aotus, and Callithrix, the lateral canal broadly intersects with the posterior canal, while in the African great apes, Theropithecus, and Cebus the canals are only minimally separated. In addition, in all extant anthropoids except hylobatids, the plane of the posterior canal forms a right angle with the anterior canal, which does not project anteriorly. Both Epipliopithecus individuals display positive scores (NMB OE 303 with lower values), overlapping with some hylobatids (mainly Hoolock) and other extant anthropoids (particularly the hominids Homo and Pongo, the platyrrhines Ateles and Alouatta, and the cercopithecoids Theropithecus and Piliocolobus). 
436 The slightly dissimilar bgPC3 scores for the two Epipliopithecus individuals result from differences in orientation between the posterior and anterior canals (obtuse angle in NHMW 1970/1397/0003 vs. right angle in NMB OE 303; SOM Fig. S2), causing a wider separation between the lateral and posterior canals (Fig. 4a-c).

When the three bgPCs are considered together, the two Epipliopithecus individuals show the greatest morphological similarities with platyrrhines (less so in NHMW 1970/1397/0003), as demonstrated by Mahalanobis distances from group centroids and by their posterior probabilities of group membership (Table 3), leading us to reject close similarities to the remaining groups for NMB OE 303, and to all anthropoid groups for NHMW 1970/1397/0003 ( $p<0.05)$. Aegyptopithecus, Parapithecus, Oreopithecus, and stem platyrrhines also closely resemble extant New World monkeys, with Oreopithecus also showing marginal affinities with cercopithecoids (Table 3). We obtain very similar results when considering all catarrhines as a single group, with all fossils being classified as platyrrhines (Table 4). For Oreopithecus and NHMW 1970/1397/0003, group membership for catarrhines cannot be rejected. However, both specimens show much lower Mahalanobis distances to the platyrrhine centroid (almost three times) than to that of catarrhines. The two Epipliopithecus individuals are closer to one another than they are to other fossil taxa (except for one individual of Homunculus, MPM-PV 3501), in turn showing similarities with stem platyrrhines, Aegyptopithecus and Oreopithecus (Table 5). A cluster analysis based on the momenta of the deformation fields confirms these results (Fig. 7). Epipliopithecus clusters with Alouatta and Ateles (large and rounded vertical canals and a large gap between the lateral and posterior canals), as well as Pithecia (obtuse angle formed by the anterior and posterior canals), within a larger cluster that includes the remaining extant platyrrhines and the other fossil taxa included in the analysis. In particular, Aegyptopithecus and Homunculus cluster with Saimiri and Cebus (flat lateral canal and similarities in the anterior canal morphology), while Oreopithecus clusters with 
Callicebus (orientation of the anterior and posterior canals). Hylobatids cluster within a larger group that also includes most cercopithecoids, and extant great apes cluster together due to their distinctive stout volumetric proportions (Urciuoli et al., 2020).

\subsection{Phylogenetic signal and phylomorphospace}

Like previous analyses (Urciuoli et al., 2020; del Rio et al., 2020; Morimoto, et al., 2020, our results indicate that the vestibule and SCs embed significant phylogenetic signal $\left(K_{\text {mult }}=1.134, p<0.001\right)$, suggesting these traits conform to a Brownian motion model of evolution, with closely related taxa resembling one another slightly more than expected ( $K_{\text {mult }}>1$ ). The phylogenetic signal computed for each bgPC separately is significant in all instances (Table 6), with bgPC1 and bgPC2 suggesting the same evolutionary mode as $\mathrm{K}_{\text {mult }}(\mathrm{K}>1)$. Conversely, we observe that the variance accumulates within clades for bgPC3 $(K<1)$, thus suggesting that changes along this axis might be more strongly affected by homoplasy.

The phylogenetic signal detected justifies the application of the phylomorphospace approach (Fig. 8). The results indicate that the reconstructed LCAs of crown anthropoids (Fig. 9a) and crown catarrhines (Fig. 9c) fall within the variability of extant New World monkeys, being very close to the platyrrhine LCA (Fig. 9b)—irrespective of the phylogenetic hypothesis used in the analysis for Epipliopithecus (i.e., stem catarrhine vs. stem hominoid, Figs. 3 and 8; SOM Fig. S3). Cercopithecoids and hominoids appear much more derived in SC morphology than platyrrhines, but in different directions. The crown anthropoid, crown platyrrhine and crown catarrhine LCAs are reconstructed as possessing large and slightly vertically-elongated canals (more so in the crown anthropoid and crown platyrrhine LCAs; Fig. 9a, b) coupled with a long CC (shorter in the crown catarrhine LCA; Fig. 9c), intermediate volumetric proportions (similar to those found in New World monkeys and cercopithecins; Fig. 10), and a coplanar lateral canal that does not intersect the plane 
of the posterior one (Fig. 9a-C). The LCA of crown catarrhines also shows a slightly more superiorly bent ampullary portion, more so than in Epipliopithecus (Fig. 9c). In contrast, the reconstructed crown hominoid LCA (Fig. 9d) is found in an area of the morphospace devoid of extant taxa and, according to our estimation, it already displayed some derived characters that are not found in Epipliopithecus (i.e., moderately vertically-compressed anterior canal, stouter canal proportions, lateral ampulla connecting more superiorly with the vestibule).

From a phenetic viewpoint, based on weighted Euclidean distances between Epipliopithecus and the bgPC scores for the reconstructed LCAs (Table 7), the former taxon is most similar to the crown catarrhine ancestral condition, and also closer to the crown anthropoid and platyrrhine LCAs, than to the ancestral conditions reconstructed for either hominoids or cercopithecoids.

We further synthesized the information provided by the phylomorphospace approach by defining seven discrete characters coded in a cladistic fashion (Table 8; Fig. 11). Their coding for the reconstructed LCAs as well as both extant and extinct anthropoids included in the analyses is reported in Table 9 and SOM Table S4. When the character states for extinct and extant taxa are analyzed against the two phylogenetic hypotheses by considering parsimony as a criterion (Table 10), Epipliopithecus is more parsimoniously interpreted as a stem catarrhine (Fig. 3a) than as a stem hominoid (Fig. 3b). The phylogenetic implications of the seven coded characters (Fig. 11; Tables 8 and 9; SOM Table S4) are discussed below and illustrated in Figure 12.

Size of the vestibule relative to the semicircular canals Extant hominids differ from all the remaining extant taxa in possessing a relatively larger vestibule, which may be thus interpreted as a synapomorphy of at least crown hominids. Among the extinct taxa, only the purported stem hominoid Oreopithecus displays the derived hominid condition, indicating either an independent acquisition of this feature in this taxon (as supported by 
our LCA reconstructions) or a secondary reversal in hylobatids. Epipliopithecus, in any case, retains the plesiomorphic condition of nonhominoid anthropoids.

Robusticity of the semicircular canals This character has the same distribution as the size of the vestibule relative to the SCs. Extant hominids and Oreopithecus differ from the remaining taxa by displaying stouter proportions. Accordingly, such proportions might be interpreted either as convergent between Oreopithecus and hominids, or as a hominoid synapomorphy with subsequent reversal in hylobatids. Our LCA reconstructions do not provide clear support for either possibility, as they suggest an intermediate ancestral condition in the overlap zone between hominoids and nonhominoid catarrhines. In either case, for this character Epipliopithecus displays the more plesiomorphic condition of nonhominoid anthropoids.

Shape of the anterior semicircular canal This character is more variable than the preceding ones, both within anthropoid subclades, and sometimes even within the same species. However, extant catarrhines generally differ from platyrrhines by possessing an anterior canal that is not superiorly elongated, being instead either rounded (as in humans and most cercopithecoids) or vertically compressed (as in great apes and generally hylobatids, although in the latter it varies intraspecifically between rounded and vertically compressed). Our LCA reconstructions suggest that the ancestral anthropoid condition-a superiorly elongated anterior canal-is symplesiomorphic not only for platyrrhines but also for the stem catarrhine Aegyptopithecus. They further support the view that a rounded anterior SC is synapomorphic of crown catarrhines, while a vertically compressed anterior SC would be synapomorphic for crown hominoids + Oreopithecus. In this regard, Epipliopithecus is more derived than Aegyptopithecus but less so than Oreopithecus. This character, therefore, unambiguously supports for Epipliopithecus a catarrhine status more derived than in Aegyptopithecus, although it would be consistent with either a stem catarrhine or a stem hominoid status. 
Shape of the anterior portion of the semicircular canal Hylobatids and orangutans differ from the rest of the sample by displaying an anterosuperiorly-projecting anterior portion of the anterior canal. This condition may be interpreted as a crown hominoid synapomorphy subsequently reversed in hominines, as further supported by the fact that Oreopithecus displays the derived condition for hominoids. Alternatively, this feature might have been independently acquired in Oreopithecus, as suggested by our LCA reconstructions, which only recover it as a hylobatid synapomorphy. Given the possession of other SC hominoid synapomorphies in Oreopithecus, we tend to favor the former interpretation, even if both are equally parsimonious. In any case, Epipliopithecus retains the more plesiomorphic condition of non-hominoid anthropoids.

Shape of the posterior semicircular canal Although this character is somewhat variable within anthropoid subclades and sometimes even within species, some generalities can be drawn. In platyrrhines, the posterior canal is generally elongated superiorly to some extent, whereas most cercopithecoids have a rounded posterior canal, and hominoids generally vary between a rounded and a vertically compressed morphology (only sometimes superiorly elongated in Pan). Our LCA reconstructions indicate that platyrrhines and Aegyptopithecus retain the ancestral anthropoid condition (superiorly elongated posterior canal), whereas the rounded morphology would be synapomorphic for crown hominoids. Epipliopithecus displays the plesiomorphic anthropoid condition and thus differs from Oreopithecus, which displays the derived catarrhine morphology.

Shape of the lateral semicircular canal ampullary portion Extant hominoids differ from the remaining extant taxa and all the analyzed extinct genera by displaying a markedly superiorly-bent ampullary portion of the lateral canal. Both Epipliopithecus and Oreopithecus thus display a more plesiomorphic condition than crown hominoids, as further confirmed by our LCA reconstructions. 
565

Length of the common crus This character is also variable to some extent, but platyrrhines generally display a longer CC than extant catarrhines, with hominoids having an even shorter CC than most cercopithecoids. Our LCA reconstructions support an intermediate length of the $\mathrm{CC}$ as synapomorphic of crown catarrhines, with a short $\mathrm{CC}$ being synapomorphic for hominoids. Epipliopithecus resembles Aegyptopithecus and platyrrhines by retaining the ancestral anthropoid condition, whereas Oreopithecus displays the derived hominoid morphology.

\section{Discussion}

Our analysis of the SC and vestibule morphology of Epipliopithecus allows us to refine our understanding of the evolution of this anatomical region in anthropoid primates and to refine previous hypotheses proposed by Urciuoli et al. (2020). The results of our deformation-based 3DGM analysis and the reconstruction of ancestral morphotypes for main anthropoid clades indicate that, like the stem catarrhine Aegyptopithecus, Epipliopithecus displays a platyrrhine-like morphology most similar to that reconstructed for the crown catarrhine LCA. This might be compatible with Epipliopithecus being either a stem catarrhine, or a crown catarrhine only slightly postdating the cercopithecoid-hominoid split. However, the fact that Epipliopithecus most closely resembles the crown anthropoid (and platyrrhine) LCAs (Table 7) suggests that the semicircular morphology of this taxon is most consistent with its status as a stem catarrhine. This conclusion is further supported by the analysis of seven discrete characters coded for this anatomical area-which indicate that this is the most parsimonious hypothesis, for reasons discussed in greater detail below.

\subsection{Epipliopithecus as a hominoid}


Based on the morphology of the SCs and vestibule, Epipliopithecus lacks multiple

591 hominoid synapomorphies, including a large vestibule relative to the canals, stout SCs, vertically-compressed anterior canal, anterosuperiorly- projecting anterior portion of the anterior canal, markedly superiorly-bent ampullary portion of the lateral canal, and short CC. Urciuoli et al.(2020) already interpreted some of these features (vertically-compressed anterior canal and markedly superiorly-bent ampullary portion of the lateral canal) as potential crown hominoid synapomorphies, whereas they interpreted others (large vestibule and stout canals) as hominid synapomorphies. Urciuoli et al. (2020) interpreted a superiorly-bent ampullary portion of the lateral canal as a hominoid synapomorphy. However, hominoids are, in fact, characterized by the possession of a markedly bent trajectory, whereas other catarrhines display a flat to slightly superiorly-bent ampullary portion of the lateral canal. This is the case for Epipliopithecus, which displays much less bending of the lateral canal than in Oreopithecus or any extant hominoid.

The possession of a large vestibule and stout canals was previously interpreted as being synapomorphic for hominids (Urciuoli et al., 2020) because hylobatids display a different ('monkey-like') condition. The differences in volumetric proportions between Epipliopithecus and hominids are particularly clear (Fig. 10), with the former closely resembling platyrrhines, Aegyptopithecus, and the inferred ancestral catarrhine condition. Given that both features are present in Oreopithecus, they may be interpreted as hominoid synapomorphies subsequently reversed in hylobatids-thereby supporting a more basal branching for Epipliopithecus. However, their interpretation as hominid synapomorphies is equally parsimonious, as it would only imply their independent acquisition in Oreopithecus. Therefore, neither a large vestibule nor stout canals can be used to unambiguously discount a hominoid status for Epipliopithecus. A similar caveat applies to the lack of an anterosuperiorly-projecting anterior canal in Epipliopithecus. This condition was previously interpreted as an autapomorphy of Hylobates (Le Maître, et al., 2017) or as a hylobatid 
synapomorphy (Spoor and Zonneveld, 1998; Urciuoli, et al. 2020). However, given its presence in orangutans and Oreopithecus, it is more readily interpreted as a hominoid synapomorphy subsequently reversed in hominines. The interpretation of some of the potential hominoid synapomorphies lacking in Epipliopithecus is ambiguous due to homoplasy (convergence and/or reversal). However, it is worth noting that, except for the markedly superiorly bent ampullary portion of the lateral canal, Oreopithecus further displays two more unambiguous hominoid synapomorphies (vertically compressed anterior canal and short (C). The absence of these features in Epipliopithecus thus conclusively excludes a more derived hominoid status for the latter as compared with Oreopithecus. Epipliopithecus also displays some hylobatid-like features in the spatial configuration between the lateral and posterior canals, as well as in the orientation between the anterior and posterior canals. According to Urciuoli et al. (2020), the lack of intersection between the lateral and posterior canals and the presence of an obtuse angle between the anterior and posterior canals would be synapomorphic for hominoids and hylobatids, respectively. However, only Hylobates consistently displays both features, while most anthropoid taxa, as well as the two Epipliopithecus individuals, show a considerable amount of intraspecific variation. Hence, we refrained from coding these features in a cladistic manner, especially in view of the low phylogenetic signal $(K<1)$ recovered for bgPC3 (accounting for the variation in the configuration of these features), which suggests a substantial degree of homoplasy. Indeed, previous analyses hypothesized that suspensory species possess more obtuse angles between the vertical canals (Gonzales et al., 2019), as this configuration provides an increased sensitivity for pitch (at the expense of roll) head movements (Muller and Verhagen, 2002a,b,c). The similarities between NHMW 1970/1397/0003, hylobatids, and some atelids (Spoor and Zonneveld, 1998; Gonzales et al., 2019) would thus agree with previous inferences about the locomotor repertoire of this taxon including some degree of suspensory behaviors 
642 (Zapfe, 1958; Fleagle, 1983; Langdon, 1986; Rose, 1994; Arias Martorell et al., 2015). In

643 contrast, the more plesiomorphic condition of NBM OE 303III (characterized by tangent 644 lateral and posterior canals, and vertical canals approximating a right angle), also found in 645 Aegyptopithecus and some nonsuspensory platyrrhine species, suggests caution when 646 using SC orientation alone for inferring positional behaviors (Perier et al., 2016; contra 647 Malinzak et al., 2012; Berlin et al., 2013).

648

4.2. Epipliopithecus as a stem catarrhine

Epipliopithecus resembles both stem platyrrhines and the stem catarrhine

Aegyptopithecus in lacking all of the aforementioned hominoid synapomorphies, thereby retaining the plesiomorphic anthropoid condition-a relatively small vestibule, slender SCs, anterosuperiorly nonprojecting anterior portion of the anterior canal, superiorly elongated posterior canal, ampullary portion of the lateral canal not markedly bent superiorly, and long CC. The fact that Epipliopithecus lacks hominoid synapomorphies displayed by Oreopithecus could still be consistent with a more basal stem hominoid status. However, such an interpretation is contradicted by the retention in Epipliopithecus of a superiorly elongated posterior canal and a long $\mathrm{CC}$ - contrasting with the rounded posterior canal and moderately short CC that are synapomorphic of crown catarrhines. The catarrhine status of Epipliopithecus and other pliopithecoids is well established based on multiple features, such as the loss of the second premolars and the presence of a $C^{1} / P_{3}$ honing complex (e.g., Harrison, 2013). The catarrhine status of Epipliopithecus is further supported by the possession of a rounded anterior canal, which is intermediate between the primitive morphology (superiorly elongated anterior canal) retained by platyrrhines and Aegyptopithecus, and the more derived (vertically compressed) morphology synapomorphic of hominoids. In this regard, Epipliopithecus is more derived toward crown catarrhines than the propliopipithecoid Aegyptopithecus, in agreement with other cranial 
668

669

670

671

672

673

674

675

676

features such as the possession of a partially enclosed tubular ectotympanic in Epipliopithecus (e.g., Harrison, 2013).

In summary, based on the morphology of the SCs and vestibule, Epipliopithecus is most parsimoniously interpreted as a stem catarrhine more derived than Aegyptopithecus, due to its possession of a crown catarrhine synapomorphy—rounded anterior canalcoupled with the lack of two additional crown catarrhine synapomorphies (superiorly elongated posterior canal and long $\mathrm{CC}$ ) and multiple hominoid and/or hominid synapomorphies as described above. The shapes of the anterior and posterior canals and CC should be considered with caution in light of the intraspecific variability displayed by these characters in some taxa (SOM Table S4). Previous analyses noted a structural relationship between the morphology of these canals and the extension of the subarcuate fossa (Jeffery and Spoor, 2006; Jeffery et al., 2008), and this relationship has been uncritically assumed in some studies (Spoor et al., 2007; Silcox et al., 2009; Gonzales et al., 2019). However, in most cases the fossa simply expands within the space left available from the ossification of the canals, with little or no influence on their shape (Jeffery et al., 2008; see also Urciuoli et al., 2020). In support of the latter hypothesis, we observe meager dissimilarities in the anterior canal morphology of NHMW 1970/1397/0003 and NBM OE 303III—except for the angle, as discussed above-irrespective of the marked differences in the morphology of the fossa between the two individuals (Zapfe, 1960). While a large amount of morphological variation has been documented within ruminant genera (Mennecart and Costeur, 2016), variation in CC length and shape has not been exhaustively analyzed in primates (Spoor and Zonneveld, 1998; Ekdale 2013; Lee et al., 2013). In the present study, we found considerable intraspecific variation in CC length for some species of monkeys and apes. Nevertheless, our results support a clear morphocline from the ancestral condition (long $\mathrm{CC}$ ) retained by platyrrhines, Aegyptopithecus, and Epipliopithecus, to the most derived condition (short CC) characteristic of hominoids, with 
694

695

696

cercopithecoids displaying an intermediate condition that is likely synapomorphic for crown catarrhines as a whole. Therefore, Epipliopithecus SC morphology supports its interpretation as more derived than Aegyptopithecus toward crown catarrhines, but excludes a crown catarrhine status and, in particular, a closer relationship with hominoids (unlike in the case of Oreopithecus).

\section{Conclusions}

Our results are in broad agreement with previous analyses suggesting that Epipliopithecus displays a 'typical monkey' inner ear morphology (Morimoto et al., 2020), while Oreopithecus possesses SC and vestibule features derived toward the crown hominoid condition (Urciuoli et al., 2020). At the same time, our study further refines previous comparisons of SC and vestibule morphology between Epipliopithecus and other anthropoids, enabling us to test competing hypotheses about the phylogenetic position of this taxon (i.e., stem catarrhine vs. stem hominoid).

From a phenetic viewpoint, for this anatomical area Epipliopithecus more closely resembles platyrrhines and the stem catarrhine Aegyptopithecus, as well as the reconstructed ancestral catarrhine morphotype. The fact that Epipliopithecus shows greater similarities with the platyrrhine and anthropoid ancestral morphotypes, rather than with those of cercopithecoids or hominoids, supports the view that Epipliopithecus is a stem catarrhine instead of a stem hominoid. From a cladistic perspective, this interpretation is confirmed based on a series of crown catarrhine and crown hominoid synapomorphies. Epipliopithecus is more parsimoniously interpreted as a stem catarrhine than as a stem hominoid based on the vestibular morphology analyzed here because it lacks several catarrhine and all hominoid synapomorphies. Specifically, the possession of a rounded posterior canal reinforces the view that Epipliopithecus is more derived than Aegyptopithecus among stem catarrhines. 
The information provided by the SCs and vestibule is thus congruent with the ectotympanic morphology of Epipliopithecus (see review in Fricano, 2018), which is more plesiomorphic than in crown catarrhines but more derived than in propliopithecoids. Some similarities between Epipliopithecus and hylobatids are based on characters that are too variable within species to be of use for phylogenetic assessment. Such features might have evolved independently between some atelids and hylobatids, due to similar locomotor-related selection pressures, and do not support the close phylogenetic link classically hypothesized between pliopithecoids and hylobatids (Hürzeler, 1954; Zapfe, 1960, 1961; Simons and Fleagle, 1973), particularly given that Epipliopithecus displays no crown hominoid synapomorphies. We therefore conclude that the SC and vestibular morphology reinforces the most commonly held view that, in accordance with most (Zalmout et al., 2010; Stevens et al., 2013; Nengo et al., 2017) but not all (Alba et al., 2015) recent cladistic analyses, Epipliopithecus is best interpreted as a stem catarrhine rather than a stem hominoid.

\section{Acknowledgements}

This research has been funded by the Agencia Estatal de Investigación (CGL201676431-P and CGL2017-82654-P, AEI/FEDER EU; and BES-2015-071318 to A.U.), the Generalitat de Catalunya (CERCA Programme, and consolidated research groups 2017 SGR 86 and 2017 SGR 116 GRC), the French Centre National de la Recherche Scientifique, the Leakey Foundation (research grant), and the Synthesys Project (AT-TAF4689; http://synthesys3.myspecies.info/), which is financed by the European Community Research Infrastructure Action under the FP7. Part of the analyses were performed using High Performance Computing resources from BSC (BCV-2020-1-0008). We are grateful to Jose Torres for the technical help provided in the setup of the analysis. We thank the following people for providing or permitting access to CT scans: Ursula Göhlich 
(Epipliopithecus NHMW 1970/1397/0003), Martin Dockner, Loïc Costeur (Epipliopithecus

NMBOE 303), Lorenzo Rook (Oreopithecus), José Braga (human specimens), Lynn

Copes, Lynn Lucas, and the MCZ (part of the scans used in the study, funded by NSF

DDIG \#0925793 and Wenner-Gren Foundation Dissertation Grant \#8102 to Lynn Copes),

Richard Kay (Homunculus and Dolichocebus), Timothy Ryan (Aegyptopithecus; funded by NSF BCS-0416164 to Timothy Ryan and the Leakey Foundation), and the Division of Fossil Primates of the Duke Lemur Center (Parapithecus). We also thank Erik Seiffert and Steven Heritage for providing a digital rendering of Parapithecus. Finally, we thank the Editor (Andrea Taylor), the Associate Editor, and three anonymous reviewers for useful comments that helped us to improve a previous version of this paper.

\section{References}

Adams, D.C., 2014. A generalized K statistic for estimating phylogenetic signal from shape and other high-dimensional multivariate data. Syst. Biol. 63, 685-697.

Adams D.C, Collyer, M.L., Kaliontzopoulou, A., 2019. Geomorph: Software for geometric morphometric analyses. R Package Version.

\section{https://cran.rproject.org/package=geomorph.}

Alba, D.M., Berning, B., 2013. On the holotype and original description of the pliopithecid Plesiopliopithecus lockeri (Zapfe, 1960). J. Hum. Evol. 65, 338-340.

Alba, D.M., Moyà-Solà, S., 2012. A new pliopithecid genus (Primates: Pliopithecoidea) from Castell de Barberà (Vallès-Penedès Basin, Catalonia, Spain). Am. J. Phys. Anthropol. 147, 88-112.

Alba, D.M., Moyà-Solà, S., Malgosa, A., Casanovas-Vilar, I., Robles, J.M., Almécija, S., Galindo, J., Rotgers, C., Bertó Mengual, J.V., 2010. A new species of Pliopithecus Gervais, 1849 (Primates: Pliopithecidae) from the Middle Miocene (MN8) of Abocador 
de Can Mata (els Hostalets de Pierola, Catalonia, Spain). Am. J. Phys. Anthropol. 141, $52-75$.

Alba, D.M., Almécija, S., DeMiguel, D., Fortuny, J., Pérez de los Ríos, M., Pina, M., Robles, J. M., Moyà-Solà, S., 2015. Miocene small-bodied ape from Eurasia sheds light on hominoid evolution. Science 350, aab2625.

Almécija, S., Tallman, L., Sallam, H.M., Fleagle, J.G., Hammond, A.S., Seiffert, E.R., 2019. Early anthropoid femora reveal divergent adaptive trajectories in catarrhine hindlimb evolution. Nat. Commun. 10, 4778.

Andrews, P.J., Harrison, T., Delson, E., Bernor, R.L., Martin, L., 1996. Distribution and biochronology of European and Southwest Asian Miocene catarrhines. In: Bernor, R.L., Fahlbusch, V., Mittmann, H. (Eds.), The Evolution of Western Eurasian Neogene Mammalian Faunas. Columbia University Press, New York, pp. 168-207.

Ankel, F., 1965. Der Canalis Sacralis als Indikator für die Länge der Caudalregion der Primaten. Folia Primatol. 3, 263-276.

Arias-Martorell, J., Alba, D.M., Potau, J. M., Bello-Hellegouarch, G., Pérez-Pérez, A., 2015. Morphological affinities of the proximal humerus of Epipliopithecus vindobonensis and Pliopithecus antiquus: Suspensory inferences based on a 3D geometric morphometrics approach. J. Hum. Evol. 80, 83-95.

Arnold, C., Matthews, L.J., Nunn, C.L., 2010. The 10kTrees website: A new online resource for primate phylogeny. Evol. Anthropol. 19, 114-118.

Beaudet, A., Dumoncel, J., Thackeray, J.F., Bruxelles, L., Duployer, B., Tenailleau, C., Bam, L., Hoffman, J., de Beer, F., Braga, J., 2016. Upper third molar internal structural organization and semicircular canal morphology in Plio-Pleistocene South African cercopithecoids. J. Hum. Evol. 95, 104-120.

Begun, D.R., 2002 The Pliopithecoidea. In: Hartwig, W.C. (Ed.), 2002. The Primate Fossil Record. Cambridge University Press, Cambridge, pp. 221-240. 
Begun, D.R., 2017. Evolution of the Pliopithecoidea. In A. Fuentes (Ed.), The International Encyclopedia of Primatology (pp. [1-4]): John Wiley \& Sons.

Berlin, J.C., Kirk, E.C., Rowe, T.B., 2013. Functional implications of ubiquitous semicircular canal non-orthogonality in mammals. PLoS One 8, e79585.

Billet, G., Hautier, L., Lebrun, R., 2015. Morphological diversity of the bony labyrinth (inner ear) in extant xenarthrans and its relation to phylogeny. J. Mammal. 96, 658-672.

Blomberg, S.P., Garland, T., Ives, A.R., 2003. Testing for phylogenetic signal in comparative data: behavioral traits are more labile. Evolution 57, 717-745.

Bône, A., Louis, M., Martin, B., Durrleman, S., 2018. Deformetrica 4: an open-source software for statistical shape analysis. In: Reuter, M., Wachinger, C., Lombaert, H., Paniagua, B., Lüthi, M., Egger, B. (Eds.), Shape in Medical Imaging. Shape MI 2018. Springer, Cham, pp. 3-13.

Bookstein, F.L., 2019. Pathologies of between-groups principal components analysis in geometric morphometrics. Evol. Biol. 46, 271-302.

Braga, J., Samir, C., Risser, L., Dumoncel, J., Descouens, D., Thackeray, J.F., Barlesque, P., Oettlé, A., Loubes, J.-M., Fradi, A., 2019a. Cochlear shape reveals that the human organ of hearing is sex-typed from birth. Sci. Rep. 9, 10889.

Bush, E.C., Simons, E.L., Dubowitz, D.J., Allman, J.M., 2004. Endocranial volume and optic foramen size in Parapithecus grangeri. In: Ross, C.F., Kay, R.F. (Eds), Anthropoid Origins: New Visions. Kluwer/Plenum, New York, pp. 603-614.

Cardini, A., O'Higgins, P., Rohlf, F.J., 2019. Seeing distinct groups where there are none: Spurious patterns from between-group PCA. Evol. Biol. 46, 303-316.

Cardini, A., Polly, P.D., 2020. Cross-validated between-group PCA scatterplots: A solution to spurious group separation? Evol. Biol. 47, 85-95. 
Casanovas-Vilar, I., Alba, D.M., Garcés, M., Robles, J.M., Moyà-Solà, S., 2011. Updated chronology for the Miocene hominoid radiation in Western Eurasia. Proc. Natl. Acad. Sci. USA 108, 5554-5559.

Ciochon, R.L., Corruccini, R.S., 1977. The phenetic position of Pliopithecus and its phylogenetic relationship to the Hominoidea. Syst. Zool. 26, 290-299.

Coleman, M.N., Colbert, M.W. 2010. Correlations between auditory structures and hearing sensitivity in non-human primates. J. Morphol. 271, 511-532.

Costeur, L., Grohé, C., Aguirre-Fernández, G., Ekdale, E., Schulz, G., Müller, B., Mennecart, B., 2018. The bony labyrinth of toothed whales reflects both phylogeny and habitat preferences. Sci. Rep. 8, 7841.

David, R., Droulez, J., Allain, R., Berthoz, A., Janvier, P., Bennequin, D., 2010. Motion from the past. A new method to infer vestibular capacities of extinct species. C.R. Palevol 9, 397-410.

David, R., Stoessel, A., Berthoz, A., Spoor, F., Bennequin, D., 2016. Assessing morphology and function of the semicircular duct system: introducing new in-situ visualization and software toolbox. Sci. Rep. 6, 32772.

del Rio, J., Aristide, L., dos Reis, S.F., dos Santos, T.M.P., Lopes, R.T., Perez, S.I., 2020. Allometry, function and shape diversification in the inner ear of platyrrhine primates. J. Mammal. Evol. https://doi.org/10.1007/s10914-019-09490-9.

Delson, E., Andrews, P.J., 1975. Evolution and interrelationships of the catarrhine primates. In: Luckett, W.P., Szalay, F.S. (Eds.), Phylogeny of the Primates: A Multidisciplinary Approach. Plenum Press, New York, pp. 405-446.

Dumoncel, J., Durrleman, S., Braga, J., Jessel, J.P., Subsol, G., 2014. Landmark-free 3D method for comparison of fossil hominins and hominids based on endocranium and EDJ shapes. Am. J. Phys. Anthropol. 153 (S58), 110. 
Durrleman, S., Pennec, X., Trouvé, A., Ayache, N., Braga, J., 2012. Comparison of the endocranial ontogenies between chimpanzees and bonobos via temporal regression and spatiotemporal registration. J. Hum. Evol. 62, 74-88.

Durrleman, S., Prastawa, M., Korenberg, J.R., Joshi, S., Trouvé, A., Gerig, G., 2012. Topology preserving atlas construction from shape data without correspondence using sparse parameters. In: Ayache, N., Delingette, H., Golland, P., Mori, K. (Eds.), Medical Image Computing and Computer-Assisted Intervention - MICCAI 2012. Springer, Berlin, pp. 223-230.

Ekdale, E.G., 2013. Comparative anatomy of the bony labyrinth (inner ear) of placental mammals. PLoS One 8, e66624.

Farris, J.S., 1989. The retention index and the rescaled consistency index. Cladistics 5, 417-419.

Fleagle, J.G., 1983. Locomotor adaptations of Oligocene and Miocene hominoids and their phyletic implications. In: Ciochon, R.L., Corruccini, R.S. (Eds.), New Interpretations of Ape and Human Ancestry. Plenum Press, New York, pp. 301-324.

Fleagle, J.G., 1984. Are there any fossil gibbons? In: Preuschoft, H., Chivers, D.J., Brockelman, W.Y., Creel, N. (Eds.), The Lesser Apes: Evolutionary and Behavioral Biology. Edinburgh University Press, Edinburgh, pp. 431-447.

Fricano, E.E.I., 2018. The primate ectotympanic tube: correlates of structure, function, and development. Ph.D. Dissertation, Johns Hopkins University.

Fulwood, E.L., Boyer, D.M., Kay, R.F., 2016. Stem members of Platyrrhini are distinct from catarrhines in at least one derived cranial feature. J. Hum. Evol. 100, 16-24.

Gilbert, C.C., Ortiz, A., Pugh, K.D., Campisano, C.J., Patel, B.A., Singh, N.P., Fleage, J.G., Patnaik, R., 2020. New middle Miocene ape (Primates: Hylobatidae) from Ramnagar, India fills major gaps in the hominoid fossil record. Proc. R. Soc. B 287, 20201655. 
872 Glaunès, J.A., Joshi, S., 2006. Template estimation form unlabeled point set data and 873 surfaces for Computational Anatomy. in: Pennec, X., Joshi, S. (Eds.), MICCAI 2006

874

875

876

877

878

879

880

881

882

883

884

885

886

887

888

889

890

891

892

893

894

895

896

Workshop Proceedings. MFCA'06 Workshop. Mathematical Foundations of

Computational Anatomy: Geometrical and Statistical Methods for Modelling Biological Shape Variability. INRIA/MICCAI, Conpenhagen, pp. 29-39.

Gonzales, L.A., Malinzak, M.D., Kay, R.F., 2019. Intraspecific variation in semicircular canal morphology_A missing element in adaptive scenarios? Am. J. Phys. Anthropol. 168, 10-24.

Grohé, C., Tseng, Z. J., Lebrun, R., Boistel, R., Flynn, J.J., 2015. Bony labyrinth shape variation in extant Carnivora: a case study of Musteloidea. J. Anat. 228, 366-383.

Grohé, C., Lee, B., Flynn, J.J., 2018. Recent inner ear specialization for high-speed hunting in cheetahs. Sci. Rep. 8, 1-8.

Harrison, T., 1982. Small-bodied apes from the Miocene of East Africa. Ph.D. Dissertation, University College London.

Harrison, T., 1987. The phylogenetic relationships of the early catarrhine primates: a review of the current evidence. J. Hum. Evol. 16, 41-80.

Harrison, T., 2005. The zoogeographic and phylogenetic relationships of early catarrhine primates in Asia. Anthropol. Sci. 113, 43-51.

Harrison, T., 2010. Dendropithecoidea, Proconsuloidea, and Hominoidea (Catarrhini, Primates). In: Werdelin, L. (Ed.), Cenozoic Mammals of Africa. University of California Press, Berkeley, pp. 429-469.

Harrison, T., 2013. Catarrhine origins. In: Begun, D.R. (Ed.), A Companion to Paleoanthropology. Blackwell Publishing, Oxford, pp. 376-396.

Harrison, T., Gu, Y., 1999. Taxonomy and phylogenetic relationships of early Miocene catarrhines from Sihong, China. J. Hum. Evol. 37, 225-277. 
Harrison, T., Zhang, Y., Wei, G., Sun, C., Wang, Y., Liu, J., Tong, H., Huang, B., Xu, F., 2020. A new genus of pliopithecoid from the late Early Miocene of China and its implications for understanding the paleozoogeography of the Pliopithecoidea. J. Hum. Evol. 145, 102838.

Harzhauser, M., Kroh, A., Mandic, O., Piller, W. E., Göhlich, U., Reuter, M., Berning, B., 2007. Biogeographic responses to geodynamics: A key study all around the OligoMiocene Tethyan Seaway. Zool. Anz. 246, 241-256.

Hürzeler, J., 1954. Contribution a l'odontologie et a la phylogénèse du genre Pliopithecus Gervais. Ann. Paleontol. 40, 5-63.

Jeffery, N., Spoor, F., 2006. The primate subarcuate fossa and its relationship to the semicircular canals part I: prenatal growth. J. Hum. Evol. 51, 537-549.

Jeffery, N., Ryan, T.M., Spoor, F., 2008. The primate subarcuate fossa and its relationship to the semicircular canals part II: Adult interspecific variation. J. Hum. Evol. 55, 326339.

Kay, R.F., Simons, E., Ross, J.L., 2009a. The basicranial anatomy of African Eocene/Oligocene anthropoids. Are there any clues for platyrrhine origins? In: Fleagle, J.G., Gilbert, C.C. (Eds.), Elwyin Simons: A Search for Origins. Springer, New York, pp. $125-158$.

Kay, R.F., Fleagle, J.G., Mitchell, T.R.T., Colbert, M., Bown, T., Powers, D.W., 2009b. The anatomy of Dolichocebus gaimanensis, a stem platyrrhine monkey from Argentina. J. Hum. Evol. 54, 323-382.

Kay, R.F., 2015. Biogeography in deep time - What do phylogenetics, geology, and paleoclimate tell us about early platyrrhine evolution? Mol. Phylogenet. Evol. 82, 358374.

Kirk, E.C., Gosselin-IIdari, A.D., 2009. Cochlear labyrinth volume and hearing abilities in primates. Anat. Rec. 292, 765-776. 
Kunimatsu, Y., Nakatsukasa, M., Shimizu, D., Nakano, Y., Ishida, H., 2019. Loss of the subarcuate fossa and the phylogeny of Nacholapithecus. J. Hum. Evol. 131, 22-27.

Langdon, J.H., 1986. Functional morphology of the Miocene hominoid foot. Contrib. Primatol. 22, $239 \mathrm{e} 257$.

Lebrun, R., P. de León, M., Tafforeau, P., Zollikofer, C., 2010. Deep evolutionary roots of strepsirrhine primate labyrinthine morphology. J. Anat 216, 368-380.

Lebrun, R., Godinot, M., Couette, S., Tafforeau, P., Zollikofer, C., 2012. The labyrinthine morphology of Pronycticebus gaudryi (Primates, Adapiformes). Palaeobiodiv. Palaeoenvir. 92, 527-537.

Lee, J.Y., Shin, K.J., Kim, J.N., Yoo, J.Y., Song, W.C., Koh, K.S., 2013. A morphometric study of the semicircular canals using micro-CT images in three-dimensional reconstruction. Anat. Rec. 269, 834-839.

Le Maître A., Schuetz, P., Vignaud, P., Brunet, M.., 2017. New data about semicircular canal morphology and locomotion in modern hominoids. J. Anat. 231, 95-109.

Macrini, T.E., Flynn, J.J., Ni, X., Croft, D.A., Wyss, A. R., 2013. Comparative study of notoungulate (Placentalia, Mammalia) bony labyrinths and new phylogenetically informative inner ear characters. J. Anat. 223, 442-461.

Malinzak, M.D., Kay, R.F., Hullar, T.E., 2012. Locomotor head movements and semicircular canal morphology in primates. Proc. Natl. Acad. Sci. USA 109, 17914 17919.

Manoussaki, D., Dimitriadis, E.K., Chadwick, R.S., 2006. Cochlea's graded curvature effect on low frequency waves. Phys. Rev. Lett. 96, 088701.

Mennecart, B., Costeur, L., 2016. Shape variation and ontogeny of the ruminant bony labyrinth, an example in Tragulidae. J. Anat. 229, 422-435. 
Mennecart, B., Rössner, G. E., Métais, G., DeMiguel, D., Schulz, G., Müller, B., Costeur, L., 2016. The petrosal bone and bony labyrinth of early to middle Miocene European deer (Mammalia, Cervidae) reveal their phylogeny. J. Morphol. 277, 1329-1338.

Mennecart, B., DeMiguel, D., Bibi, F., Rössner, G.E., Métais, G., Neenan, J.M., Wang, S., Schulz, G, Müller, B., Costeur, L., 2017. Bony labyrinth morphology clarifies the origin and evolution of deer. Sci. Rep. 7, 13176.

Mitteroecker, P., Bookstein, F., 2011. Linear discrimination, ordination, and the visualization of selection gradients in modern morphometrics. Evol. Biol. 38, 100-114.

Moyà-Solà, S., Köhler, M., 2000. Comprendere Oreopithecus bambolii, un ominoide fossile enigmatico. Atti Mus. St. Nat. Maremma 18, 39-65.

Moyà-Solà, S., Köhler, M., Alba, D.M., 2001. Egarapithecus narcisoi, a new genus of Pliopithecidae (Primates, Catarrhini) from the late Miocene of Spain. Am. J. Phys. Anthropol. 114, 312-324.

Morimoto, N., Kunimatsu, Y., Nakatsukasa, M., Ponce de León, M. S., Zollikofer, C. P., Ishida, H., Sasaki, T., Suwa, G., 2020. Variation of bony labyrinthine morphology in Mio-Plio-Pleistocene and modern anthropoids. Am. J. Phys. Anthropol. 173, 276-292.

Muller, M., Verhagen, J.H.G., 2002a. Optimization of the mechanical performance of a two-duct semicircular duct system-Part 1: dynamics and duct dimensions. J. Theor. Biol. 216, 409-424.

Muller, M., Verhagen, J.H.G., 2002b. Optimization of the mechanical performance of a two-duct semicircular duct system—Part 2: excitation of endolymph movements. J. Theor. Biol. 216, 425-442.

Muller, M., Verhagen, J.H.G., 2002c. Optimization of the mechanical performance of a two-duct semicircular duct system-Part 3: the positioning of the ducts in the head. J. Theor. Biol. 216, 443-459. 
Nengo, I., Tafforeau, P., Gilbert, C.C., Fleagle, J.G., Miller, E.R., Feibel, C., Fox, D.L., Feinberg, J., Pugh, K.D., Berruyer, C., Mana, S., Engle, Z., Spoor, F., 2017. New infant cranium from the African Miocene sheds light on ape evolution. Nature 548, 169-174.

Pagel, M., 1999. Inferring the historical patterns of biological evolution. Nature 401, 877884.

Perier, A., Lebrun, R., Marivaux, L., 2016. Different level of intraspecific variation of the bony labyrinth morphology in slow- versus fast-moving Primates. J. Mammal. Evol. 23, 353-368.

R Core Team, 2019. R: A language and environment for statistical computing. R Foundation for Statistical Computing, Vienna.

Rae, T.C., Johnson, P.M., Yano, W., Hirasaki, E. 2016. Semicircular canal size and locomotion in colobine monkeys: a cautionary tale. Folia Primatol. 87, 213-223.

Revell, L.J., 2012. Phytools: an R package for phylogenetic comparative biology (and other things). Methods Ecol. Evol. 3, 217-223.

Rook, L., Renne, P., Benvenuti, M., Papini, M., 2000. Geochronology of Oreopithecusbearing succession at Baccinello (Italy) and the extinction pattern of european miocene hominoids. J. Hum. Evol. 39, 577-582.

Rook, L., Bondioli, L., Casali, F., Rossi, M., Köhler, M., Moyá Solá, S., Macchiarelli, R., 2004. The bony labyrinth of Oreopithecus bambolii. J. Hum. Evol. 46, 347-354.

Rose, M.D., 1994. Quadrupedalism in some Miocene catarrhines. J. Hum. Evol. 26, 387411.

Russo, G.A., 2016. Comparative sacral morphology and the reconstructed tail lengths of five extinct primates: Proconsul heseloni, Epipliopithecus vindobonensis, Archaeolemur edwardsi, Megaladapis grandidieri, and Palaeopropithecus kelyus. J. Hum. Evol. 90, 135-162. 
Ryan, T.M., Silcox, M.T., Walker, A., Mao, X., Begun, D.R., Benefit, B.R., Gingerich, P.D., Köhler, M., Kordos, L., McCrossin, M.L., Moyà-Solà, S., Sanders, W.J., Seiffert, E.R., Simons, E., Zalmout, I.S., Spoor, F., 2012. Evolution of locomotion in Anthropoidea: the semicircular canal evidence. P. Roy. Soc. B. 279, 3467-3475.

Sankhyan, A. R., Kelley, J., \& Harrison, T. 2017. A highly derived pliopithecoid from the Late Miocene of Haritalyangar, India. Journal of Human Evolution 105, 1-12.

Savje, F. 2019. distances: tools for distance metrics. https://cran.rproject.org/web/packages/distances/index.html.

Schlager, S., 2017. Morpho and Rvcg - shape analysis in R: R-packages for geometric morphometrics, shape analysis and surface manipulations. In: Zheng, G., Li, S., Székely, G. (Eds.), Statistical Shape and Deformation Analysis. Methods, Implementation and Applications. Academic Press, London, pp. 217-256.

Seiffert, E.R., 2006. Revised age estimates for the later Paleogene mammal faunas of Egypt and Oman. Proc. Natl. Acad. Sci. USA 103, 5000-5005.

Sidlauskas, B., 2008. Continuous and arrested morphological diversification in sister clades of characiform fishes: a phylomorphospace approach. Evolution 62, 31353156.

Silcox, M.T., Bloch, J.I., Boyer, D.M., Godinot, M., Ryan, T.M., Spoor, F., Walker, A., 2009. Semicircular canal system in early primates. J. Hum. Evol. 56, 315-327.

Simons, E.L., Fleagle, J.G., 1973. The history of extinct gibbon-like primates. In:

Rumbaugh, D.M. (Ed.), Gibbon and Siamang Vol. 2. Anatomy, Dentition, Taxonomy, Molecular Evolution and Behavior. Karger, Basel, pp. 121-148.

Simons, E.L., Seiffert, E.R., Ryan, T.M., Attia, Y., 2007. A remarkable female cranium of the early Oligocene anthropoid Aegyptopithecus zeuxis (Catarrhini, Propliopithecidae). Proc. Natl. Acad. Sci. USA 104, 8731-8736. 
1023

1024

1025

1026

1027

1028

1029

1030

1031

1032

1033

1034

1035

1036

1037

1038

1039

1040

1041

1042

1043

1044

1045

1046

1047

Spoor, F., Zonneveld., F., 1998. Comparative review of the human bony labyrinth. Yearb. Phys. Anthropol. 41, 211-251.

Spoor, F., Garland, T., Krovitz, G., Ryan, T.M., Silcox, M.T., Walker, A., 2007. The primate semicircular canal system and locomotion. Proc. Natl. Acad. Sci. USA 104, 1080810812.

Stevens, N.J., Seiffert, E.R., O'Connor, P.M., Roberts, E.M., Schmitz, M.D., Krause, C., Gorscak, E., Ngasala, S., Hieronymus, T.L., Temu, J., 2013. Palaeontological evidence for an Oligocene divergence between Old World monkeys and apes. Nature 497, 611-614.

Swofford, D., 2003. PAUP*. Phylogenetic Analysis Using Parsimony ( ${ }^{*}$ and Other Methods). Version 4. Sinauer Associates, Sunderland.

Szalay, F.S., 1975. Phylogeny of primate higher taxa: the basicranial evidence. In: Luckett, W.P., Szalay, F.S. (Eds.), Phylogeny of the Primates: A Multidisciplinary Approach.

Plenum Press, New York, pp. 91-125.

Szalay, F.S., Delson, E., 1979. Evolutionary History of the Primates. Academic Press, New York.

Tejedor, M.F., Rosenberger, A.L., 2008. A neotype for Homunculus patagonicus Ameghino, 1891, and a new interpretation of the taxon. PaleoAnthropology 2008,6882.

Urciuoli, A., Zanolli, C., Begun, D.R., Almécija, S., Dumoncel, J., Moyà-Solà, S., Alba, D.M., 2019. A deformation-based geometric morphometric analysis of the vestibular apparatus in the Miocene apes Hispanopithecus laietanus and Rudapithecus hungaricus. Am. J. Phys. Anthropol. 168 (S68), 253.

Urciuoli, A., Zanolli, C., Beaudet, A., Dumoncel, J., Santos, F., Moyà-Solà, S., Alba, D.M., 2020. The evolution of the vestibular apparatus in apes and humans. eLife 9, e51261. 
van der Meulen, A.J., García-Paredes, I., Álvarez-Sierra, M.Á., van den Hoek Ostende, L.W., Hordijk, K., Oliver, A., López-Guerrero, P., Hernández-Ballarín, V., PeláezCampomanes, P., 2011. Biostratigraphy or biochronology? Lessons from the Early and Middle Miocene small Mammal Events in Europe. Geobios 44, 309-321.

Zalmout, I.S., Sanders, W.J., MacLatchy, L., Gunnell, G., Al-Mufarreh, Y.A., Ali, M.A., Nasser, A.-A. H., Al-Masary, A.M., Al-Sobhi, S.A., Nadhra, A.O., Matari, A.H., Wilson, J. A., Gingerich, P. D., 2010. New Oligocene primate from Saudi Arabia and the divergence of apes and Old World monkeys. Nature 466, 360-365.

Zapfe, H., 1958. The skeleton of Pliopithecus (Epipliopithecus) vindobonensis Zapfe and Hürzeler. Am. J. Phys. Anthropol. 16, 441-457.

Zapfe, H., 1961. Die Primatenfunde aus der miozänen Spaltenfüllung von Neudorf an der March (Děvínská Nová Ves), Tschechoslowakei. Schweizer. palaeontol. Abh. 78, 1293.

Zapfe, H., Hürzeler, J., 1957. Die Fauna der miozänen Spaltenfüllung von Neudorf an der March (ČSR.). Primates. Sitzungsber. Öst. Akad. Wiss. Math. Naturwiss. KI. 166, 113123. 

Table 1. Digital object identifiers (DOIs) of the 3D virtual models of the vestibule and semicircular canals of Epipliopithecus vindobonensis available from MorphoSource.org (https://www.morphosource.org).

Catalog No.

NMBOE 303a (individual III)

NMBOE 303b (individual III)

NHMW 1970/1397/0003 (individual II)

\section{Museum}

NMBOE https://doi.org/10.17602/M2/M113935

NMBOE $\quad$ https://doi.org/10.17602/M2/M113933

NHMW $\quad$ https://doi.org/10.17602/M2/M113932

1069 Abbreviations: NMB OE = Naturhistorisches Museum Basel, Switzerland; NHMW = 1070 Naturhistorisches Museum Wien, Austria. 
Table 2. Log-transformed cube root of canal volume (In VolSC, $\mathrm{mm}^{3}$ ) and logtransformed canal length ( $\mathrm{In} \mathrm{L,} \mathrm{mm}$ ) measured for the fossil taxa included in the

Catalog No.

NMBOE 303a

NMBOE 303b

NHMW 1970/1397/0003

CGM 85785

MPM-PV 30501

MPM-PV 30502

MPM-PV 30503

MACN 14128

BAC 208

DPC 18651
Taxon

Epipliopithecus vindobonensis

Epipliopithecus vindobonensis

Epipliopithecus vindobonensis

Aegyptopithecus zeuxis

Homunculus patagonicus

Homunculus patagonicus

Homunculus patagonicus

Dolichocebus gaimanensis

Oreopithecus bambolii

Parapithecus grangeri
In VolsC

$\ln \mathrm{L}$

Abbreviations: BAC = Baccinello (field acronym; housed at Naturhistorisches Museum Basel, Switzerland); CGM = Egyptian Geological Museum, Cairo, Egypt; MPM$\mathrm{PV}=$ Museo Regional Provincial Padre M.J. Molina, Río Gallegos, Argentina;

MACN = Museo Argentino de Ciencias Naturales, Buenos Aires, Argentina; DPC = Duke Lemur Center, Durham, NC, USA. 
Table 3. Mahalanobis distances $\left(D^{2}\right)$ and posterior probabilities of group membership $(p)$ based on the scores for fossil specimens in the between-group principal component analysis for the entire anthropoid sample..,$\underline{b}$

$D^{2}$

Epipliopithecus vindobonensis (NHMW
1970/1397/0003)
Epipliopithecus vindobonensis (NMB OE
303a)

Epipliopithecus vindobonensis (NMB OE 303b)

Oreopithecus bambolii (BAC 208)

Aegyptopithecus zeuxis (CGM 85785)

Homunculus patagonicus (MPM-PV 3501)

Homunculus patagonicus (MPM-PV 3502) 10.336

Homunculus patagonicus (MPM-PV 3503) 10.083

Dolichocebus gaimanensis (MACN 14128) 5.204

Parapithecus grangeri (DPC 18651)

$$
P
$$

Epipliopithecus vindobonensis (NHMW 1970/1397/0003)

Epipliopithecus vindobonensis (NMB OE $\quad 0.018$ 303a)

Epipliopithecus vindobonensis (NMB OE 303b)

Oreopithecus bambolii (BAC 208)

Aegyptopithecus zeuxis (CGM 85785)

Homunculus patagonicus (MPM-PV 3501) 0.003

Homunculus patagonicus (MPM-PV 3502) 0.003

Homunculus patagonicus (MPM-PV 3503) 0.019

\section{Cerco}

17.179

12.190

3.307

8.083

12.430

6.533

0.006

0.013

0.052

0.001
Cercopithecoidea

$<0.00$

$<0.00$

$<0.001$

0.001

$<0.001$

0.848 
$\mathbf{D}^{2}$

Dolichocebus gaimanensis (MACN 14128)

Parapithecus grangeri (DPC 18651)
Cercopithecoidea Hominidae Hylobatidae Platyrrhini

0.013

$<0.001<0.001$

0.612

0.002

$<0.001$

$<0.001$

0.411

Abbreviations: NHMW = Naturhistorisches Museum of Wien, Austria;

$\mathrm{NMB}=$ Naturhistorisches Museum of Basel, Switzerland; $\mathrm{BAC}=\mathrm{NMB}$ accession number for Oreopithecus bambolii specimens; CGM = Egyptian Geological Museum, Cairo, Egypt; MPM-PV = Museo Regional Provincial Padre M.J. Molina, Río Gallegos, Argentina;

MACN = Museo Argentino de Ciencias Naturales, Buenos Aires, Argentina; DPC = Duke Lemur Center, Durham, NC, USA. a

Note that these are probability estimates of having a particular score given membership in a particular group, not the likelihood of group membership in each of the a priori defined groups given a particular score (the greater the number, the higher the probability).

b

The lowest distance $\left(D^{2}\right)$ and highest posterior probability of group membership $(p)$ for each specimen are bolded. 
Table 4. Mahalanobis distances $\left(\mathrm{D}^{2}\right)$ and posterior probabilities of group membership (p) based on the scores for fossil specimens in the between-group principal component analysis for the entire anthropoid sample and considering all catarrhines as a single group. ${ }^{\text {ab }}$

$\mathbf{D}^{2}$

Epipliopithecus vindobonensis (NHMW 1970/1397/0003)

Epipliopithecus vindobonensis (NMB OE 303a)

Epipliopithecus vindobonensis (NMB OE 303b)

Oreopithecus bambolii (BAC 208)

Aegyptopithecus zeuxis (CGM 85785)

Homunculus patagonicus (MPM-PV 3501)

Homunculus patagonicus (MPM-PV 3502)

Homunculus patagonicus (MPM-PV 3503)

Dolichocebus gaimanensis (MACN 14128)

Parapithecus grangeri (DPC 18651)

$P$

Epipliopithecus vindobonensis (NHMW 1970/1397/0003)

Epipliopithecus vindobonensis (NMB OE 303a)

Epipliopithecus vindobonensis (NMB OE 303b)

Oreopithecus bambolii (BAC 208)

Aegyptopithecus zeuxis (CGM 85785)

Homunculus patagonicus (MPM-PV 3501)

Homunculus patagonicus (MPM-PV 3502)

Homunculus patagonicus (MPM-PV 3503)

Dolichocebus gaimanensis (MACN 14128)

Parapithecus grangeri (DPC 18651)

\section{Catarrhini Platyrrhini}

$$
13.016
$$

5.341

11.837

1.654

13.040

2.098

9.085

3.890

16.900

3.204

13.814

0.135

13.057

0.284

10.989

1.806

8.645

2.417

12.592

3.670

Catarrhini

Platyrrhini

0.109

0.241

0.022

0.876

0.017

0.847

0.124

0.673

0.002

0.886

0.002

0.985

0.002

0.968

0.034

0.935

0.013

0.841

0.002

0.795 
1101 Abbreviations: NHMW = Naturhistorisches Museum of Wien, Austria;

$1102 \mathrm{NMB}=$ Naturhistorisches Museum of Basel, Switzerland; BAC = NMB accession number for Oreopithecus bambolii specimens; CGM = Egyptian Geological Museum, Cairo, Egypt; MPM-PV = Museo Regional Provincial Padre M.J. Molina, Río Gallegos, Argentina; Lemur Center, Durham, NC, USA.

a

Note that these are probability estimates of having a particular score given membership in a particular group, not the likelihood of group membership in each of the a priori defined groups given a particular score (the greater the number, the higher the probability). b

The lowest distance and highest probability for each specimen are bolded. 
Table 5. Mahalanobis distances $\left(\mathrm{D}^{2}\right)$ between specimens of Epipliopithecus and other fossils based on between group principal component analysis scores.

$D^{2}$ 1970/1397/0003)

Epipliopithecus vindobonensis (NMB OE 303a)

Epipliopithecus vindobonensis (NMB OE 303b)

Oreopithecus bambolii (BAC 208)

Aegyptopithecus zeuxis (CGM 85785)

Homunculus patagonicus (MPM-PV 3501)

Homunculus patagonicus (MPM-PV 3502)

Homunculus patagonicus (MPM-PV 3503)

Dolichocebus gaimanensis (MACN 14128)

Parapithecus grangeri (DPC18651)
NHMW 1970/1397/0003
NMB OE 303a
NMB OE $303 b$

$\begin{array}{lll}- & 1.332 & 1.285\end{array}$

$\begin{array}{lll}1.332 & - & 0.176\end{array}$

$1.285 \quad 0.176 \quad-$

$\begin{array}{lll}2.244 & 1.901 & 2.055\end{array}$

$\begin{array}{lll}2.360 & 1.804 & 1.927\end{array}$

$\begin{array}{lll}1.943 & 0.919 & 1.033\end{array}$

$\begin{array}{lll}2.246 & 1.251 & 1.388\end{array}$

$\begin{array}{lll}1.914 & 1.450 & 1.592\end{array}$

$\begin{array}{lll}3.081 & 2.077 & 2.243\end{array}$

$\begin{array}{lll}3.201 & 2.017 & 2.161\end{array}$

1115 Abbreviations: NHMW = Naturhistorisches Museum Wien, Austria; NMB

$1116 \mathrm{OE}=$ Naturhistorisches Museum Basel, Switzerland; BAC = Baccinello (housed at NMB); 1117 CGM = Egyptian Geological Museum, Cairo, Egypt; MPM-PV = Museo Regional Provincial 1118 Padre M.J. Molina, Río Gallegos, Argentina; MACN = Museo Argentino de Ciencias 1119 Naturales, Buenos Aires, Argentina; DPC = Duke Lemur Center, Durham, NC, USA. 
Table 6. Phylogenetic signal computed for the between-group principal analysis

1121 applied to the deformation fields of the extant anthropoid comparative sample. The variance explained by each principal component (bgPC) and the $p$-value for the statistics are given within parentheses.

$$
\text { bgPC1 (59\%) }
$$

Pagel's $\lambda$ $1.000(p<0.0001)$

$1.148(p<0.0001)$
bgPC2 (30\%)

$0.843(p<0.0001)$

$1.446(p<0.001)$
bgPC3 (11\%)

$0.925(p<0.0001)$

$0.732(p<0.001)$ 
1124

1125

1126

Table 7. Weighted Euclidean distances computed between the between-group principal component scores of the reconstructed last common ancestors (LCAs) and the Epipliopithecus centroid.

LCA

Crown anthropoids

Crown platyrrhines

Crown catarrhines

Crown cercopithecoids

Crown hominoids

\section{Distance}

1.141

0.989

1.646

1.256 
Table 8. Definition of the discrete characters of semicircular canal (SC) and vestibule morphology used in this paper.

\section{Character}

Character statements (characters + character states) ${ }^{\mathrm{a}}$

No.

$\# 1$

\#2

\#3

\#4

\#5

\#6

\#7
Size of the vestibule relative to the SCs: $0=$ small; $1=$ large.

Robusticity of the SCs: $0=$ slender; 1 = stout.

Shape of the anterior SC: 0 = vertically compressed; 1 = rounded; 2 = elongated superiorly.

Shape of the anterior portion of the anterior SC: $0=$ non-projecting anterosuperiorly; $1=$ anterosuperiorly projecting.

Shape of the posterior SC: 0 = vertically compressed; 1 = rounded; $2=$ elongated superiorly.

Shape of the lateral SC ampullary portion: 0 = flat or only slightly bent superiorly; $1=$ markedly bent superiorly.

Length of the CC: $0=$ long; 1 = intermediate; 2 = short. 
Table 9. Character states coded for the estimated last common ancestors (LCAs) and for the fossil taxa included in the analysis. ${ }^{\text {. }}$.

Species/LCAs

Epipliopithecus vindobonensis

Aegyptopithecus zeuxis

Dolichocebus gaimanensis

Homunculus patagonicus

Oreopithecus bambolii

Parapithecus grangeri

Crown anthropoid LCA

Crown platyrrhine LCA

Crown catarrhine LCA

Crown cercopithecoid LCA

Crown hominoid LCA

Crown hylobatid LCA

Crown hominid LCA $\begin{array}{llllll}\# 1 & \# 2 & \# 3 & \# 4 & \# 5 & \# 6\end{array}$

$\begin{array}{lllllll}0 & 0 & 1 & 0 & 2 & 0 & 0\end{array}$

$\begin{array}{lllllll}0 & 0 & 2 & 0 & 2 & 0 & 0\end{array}$

$\begin{array}{lllllll}0 & 0 & 2 & 0 & 2 & 0 & 0\end{array}$

$\begin{array}{lllllll}0 & 0 & 2 & 0 & 0,2 & 0 & 0\end{array}$

$\begin{array}{lllllll}1 & 1 & 0 & 1 & 1 & 0 & 2\end{array}$

$\begin{array}{lllllll}0 & 0 & 2 & 0 & 2 & 0 & 0\end{array}$

$\begin{array}{lllllll}0 & 0 & 2 & 0 & 2 & 0 & 0\end{array}$

$\begin{array}{lllllll}0 & 0 & 2 & 0 & 2 & 0 & 0\end{array}$

$\begin{array}{lllllll}0 & 0 & 1 & 0 & 1 & 0 & 1\end{array}$

$\begin{array}{lllllll}0 & 0 & 1 & 0 & 1 & 0 & 1\end{array}$

$\begin{array}{lllllll}0 & 0 & 0 & 0 & 1 & 1 & 2\end{array}$

$\begin{array}{lllllll}0 & 0 & 0 & 1 & 1 & 1 & 2\end{array}$

$\begin{array}{lllllll}1 & 1 & 0 & 0 & 1 & 1 & 2\end{array}$
a 

hypotheses (i.e., stem catarrhine vs. stem hominoid) discussed in this paper for Epipliopithecus. The higher the index, the more parsimonious the hypothesis. ${ }^{\text {. }}$ Metrics

Stem catarrhine (Fig. 3 a)
Stem hominoid (Fig. 3b)
Tree length

$\mathrm{Cl}$

$\mathrm{RI}$

0.826

0.376
24

0.417

0.797

0.332

1138 Abbreviations: $\mathrm{Cl}=$ consistency index; $\mathrm{RI}=$ retention index; $\mathrm{RC}=$ rescaled consistency 1139 index. 


\section{Figure captions}

Figure 1. Illustration of the protocol used for digitally separating the cochlea (green) from the semicircular canals and the vestibule (blue). a) In anterior view, the first landmark (yellow filled circle) is placed anteriorly to the oval window, on the point of maximum surface curvature of the ridge-like morphology formed by the narrowing of the vestibule. b) In posterior view, three landmarks are placed along the junction between the bony vestibule and the cochlea, defined by the line of maximum surface curvature found immediately below the bulge formed by the saccular recess. A cutting plane (here perpendicular to the view and depicted by a black line) is best fitted to the identified landmarks using the 'Points To Fit' option of the 'Clipping Plane' module of Avizo version 9.0.1 (FEI Visualization Sciences Group, Houston) via a customized script (available upon request to A.U.), and used as a reference for a straight cut. Abbreviations: asc $=$ anterior semicircular canal; psc $=$ posterior semicircular canal; Isc = lateral semicircular canal; CC $=$ common crus.

Figure 2. Cladogram of extant and fossil anthropoids showing the two phylogenetic hypotheses for Epipliopithecus. The solid line (A) denotes the most widely accepted phylogenetic position of Epipliopithecus as a stem catarrhine, whereas the dashed line (B) denotes the alternative hypothesis that Epipliopithecus would be more closely related to hominoids. Key nodes are highlighted as follows: gray circle = crown anthropoids; green circle $=$ crown platyrrhines; blue circle $=$ crown catarrhines orange circle $=$ crown hominoids. Skulls and crania (not to scale) were taken from the following sources for illustrative purposes only: extant skulls and Aegyptopithecus, Wikimedia Commons; Dolichocebus, Kay et al. (2009b: Fig. 1); Homunculus, Tejedor and Rosenberger (2008: Fig. 2); Oreopithecus (reconstruction), Moyà-Solà and Köhler (2000: Fig. 5); 
1168 Epipliopithecus, photograph of a cast; Parapithecus, digital reconstruction with 1169 photographic texture made by Steven Heritage.

Figure 3. Phylogenetic trees used for the phylomorphospace approach. They differ in considering Epipliopithecus as a stem catarrhine (a) or a stem hominoid (b).

Figure 4. Rendered 3D models of the semicircular canals and vestibule of Epipliopithecus vindobonensis (all specimens depicted as from the left side) and selected extant anthropoids, in lateral (left), superior (middle), and posterior (right) views: a) E. vindobonensis (individual II, NHMW 1970/1397/0003, mirrored); b) E. vindobonensis

1178 (individual III, NMB OE 303a); c) E. vindobonensis (individual III, NMB OE 303b, mirrored); d) Parapithecus grangeri (DPC 18651); e) Dolichocebus gaimanensis (MACN 14128); f) Homunculus patagonicus (MPM-PV 3501); g) Ateles geoffroyi (MCZ 29628); h) Alouatta palliata (DU EA LP12); i) Cebus apella (MCZ27891); j) Aegyptopithecus zeuxis (CGM 85785); k) Trachypithecus cristatus (MCZ35603); I) Chlorocebus pygerythrus (SIU 4796); m) Macaca fascicularis (MCZ 35765); n) Oreopithecus bambolii (BAC 208); o) Hylobates Iar (MCZ 41424); p) Symphalangus syndactylus (AMNH.M 106583); q) Hoolock hoolock (AMNH.M 83425); r) Pongo pygmaeus (IPS10647); s) Gorilla gorilla (AMNH.M 167338; t) Pan paniscus (MCZ 38019); u) Homo sapiens (EMBR 179). Scale bars equal $5 \mathrm{~mm}$.

Figure 5. Bivariate plot of canal log-transformed cube root canal volume (mm; Ln VolSC) vs. log-transformed canal length ( $\mathrm{mm}$; In L). Separate regression lines are depicted for hominids (red line) and for nonhominid anthropoids (blue line). Epipliopithecus (NHMW 1970/1397/0003 and NMB OE 303a, b) falls within the variability of nonhominid 1192 anthropoids, similar to all extinct taxa except Oreopithecus. Measurements for the included 1193 fossil taxa given in Table 6. 
1195

1196

Figure 6. Patterns of vestibule and semicircular canal shape variation among major anthropoid clades based on the results of a between-group principal component analysis, as depicted by bivariate plots between principal components (bgPCs): a) bgPC2 vs. bgPC1; b) bgPC3 vs. bgPC1. Variance explained by each component is given along each axis. c-e) Extreme conformations of maximum (above) and minimum (below) bgPC scores: c) bgPC1; d) bgPC2; e) bgPC3. Four groups (platyrrhines, cercopithecoids, hylobatids, and hominids) were defined a priori, whereas specimens of Epipliopithecus vindobonensis were plotted post hoc onto the morphospace. Renderings in lateral (left), superior (middle), and posterior (right) views of warped 3D models representing the extreme conformations for each bgPC are placed close to the corresponding axis. Convex hulls depict the range of variation for a priori defined groups using the following color code: green $=$ platyrrhines; blue $=$ cercopithecoids; red $=$ hylobatids; orange $=$ hominids .

Figure 7. Dendrogram resulting from a cluster analysis (Ward's method) based on Mahalanobis distances computed between the species centroids of the between-group principal component analysis (bgPCA) of shape data. The cophenetic correlation coefficient is 0.703 .

Figure 8. Phylomorphospace of the anthropoid semicircular canal. The phylogenetic tree (with Epipliopithecus included as a stem catarrhine; Fig. 3a) is projected onto the tangent space defined by the between-group principal components (bgPCs) as depicted in Figure 6. The internal nodes (i.e., the ancestral states) were estimated using maximum likelihood: a) bgPC2 vs. bgPC1; b) bgPC3 vs. bgPC1. Variance explained by each component is given along each axis. Convex hulls depict the range of variation for a priori defined groups using the following color code: green = platyrrhines; blue = cercopithecoids; red = 
1220 hylobatids; orange = hominids. The ancestral nodes discussed for assessing

1221 Epipliopithecus phylogenetic affinities do not change consistently in their position in the

1222

1223

1224

1225

1226

1227

1228

1229

1230

1231

1232

1233

1234

1235

1236

1237

1238

1239

1240

1241

1242

1243

1244

morphospace irrespective of the phylogenetic hypothesis used for their estimation (see

SOM Fig. S3 for the alternative phylogenetic tree including Epipliopithecus as a stem

hominoid). Key nodes are highlighted as follows: gray circle = crown anthropoids; green

circle $=$ crown platyrrhines; blue circle = crown catarrhines; orange circle $=$ crown hominoids.

Figure 9. Reconstruction of the semicircular canals and vestibule for the last common ancestors (LCAs) of the following clades: a) crown anthropoids; b) crown platyrrhines; c) crown catarrhines; d) crown hominoids. The renderings of each 3D model are depicted in lateral (left), superior (middle), and posterior (right) views.

Figure 10. Box-and-whisker plot of allometric residuals based on best-fit line of the nonhominid anthropoid regression of log-transformed cube root of canal volume and logtransformed canal length (as depicted in Fig. 5). Vertical lines correspond to the median, boxes depict interquartile range, whiskers represent maximum and minimum values within 1.5 times the interquartile range, and black dots are outliers. Sample sizes for extant groups are the following: Platyrrhini $(n=40)$, Cercopithecoidea $(n=75)$, Hylobatidae $(n=$ 17), Hominidae $(n=30)$.

Figure 11. Illustration of the discrete characters of semicircular canal (SC) and vestibule morphology used in this paper. Numbers preceding each state $(0,1,2)$ correspond to character states numbered in Tables 8 and 9, and SOM Table S4. 
1245 Figure 12. Simplified cladogram of crown anthropoids and selected extinct catarrhines 1246 (Epipliopithecus and Oreopithecus) summarizing the main synapomorphies inferred for the 1247 various clades in semicircular canal and vestibule morphology. The four extant anthropoid 1248 clades distinguished (platyrrhines, cercopithecoids, hylobatids and hominids) are depicted 1249 as terminal nodes. The synapomorphies inferred for each node are summarized below; 1250 character number (preceded by a hash) and character state (within parentheses) are 1251 provided after each synapomorphy within brackets. a) Epipliopithecus + crown catarrhines: 1252 rounded anterior canal [\#3(1)]; b) Crown catarrhines: rounded posterior canal [\#5(1)], 1253 moderately short CC [\#7(1)]; c) Oreopithecus + crown hominoids: vertically compressed 1254 anterior canal [\#3(0)], anterosuperiorly-projecting anterior portion of the anterior canal 1255 [\#4(1)], short CC [\#7(2)]; d) Crown hominoids: markedly superiorly bent ampullary portion 1256 of the lateral canal [\#6(1)]; e) Crown hominids (unless Oreopithecus + crown hominoid 1257 synapomorphies [node c] with reversal in hylobatids): large vestibule relative to the SCs 1258 [\#1(1)], stout SCs [\#2(1)]. Abbreviations: $C C=$ common crus; $S C=$ semicircular canals. 1259 See Figure 11 for an illustration of the various character states and Table 9 and SOM 1260 Table S4 for the scoring of reconstructed last common ancestors and individual taxa, 1261 respectively. 


$$
b
$$




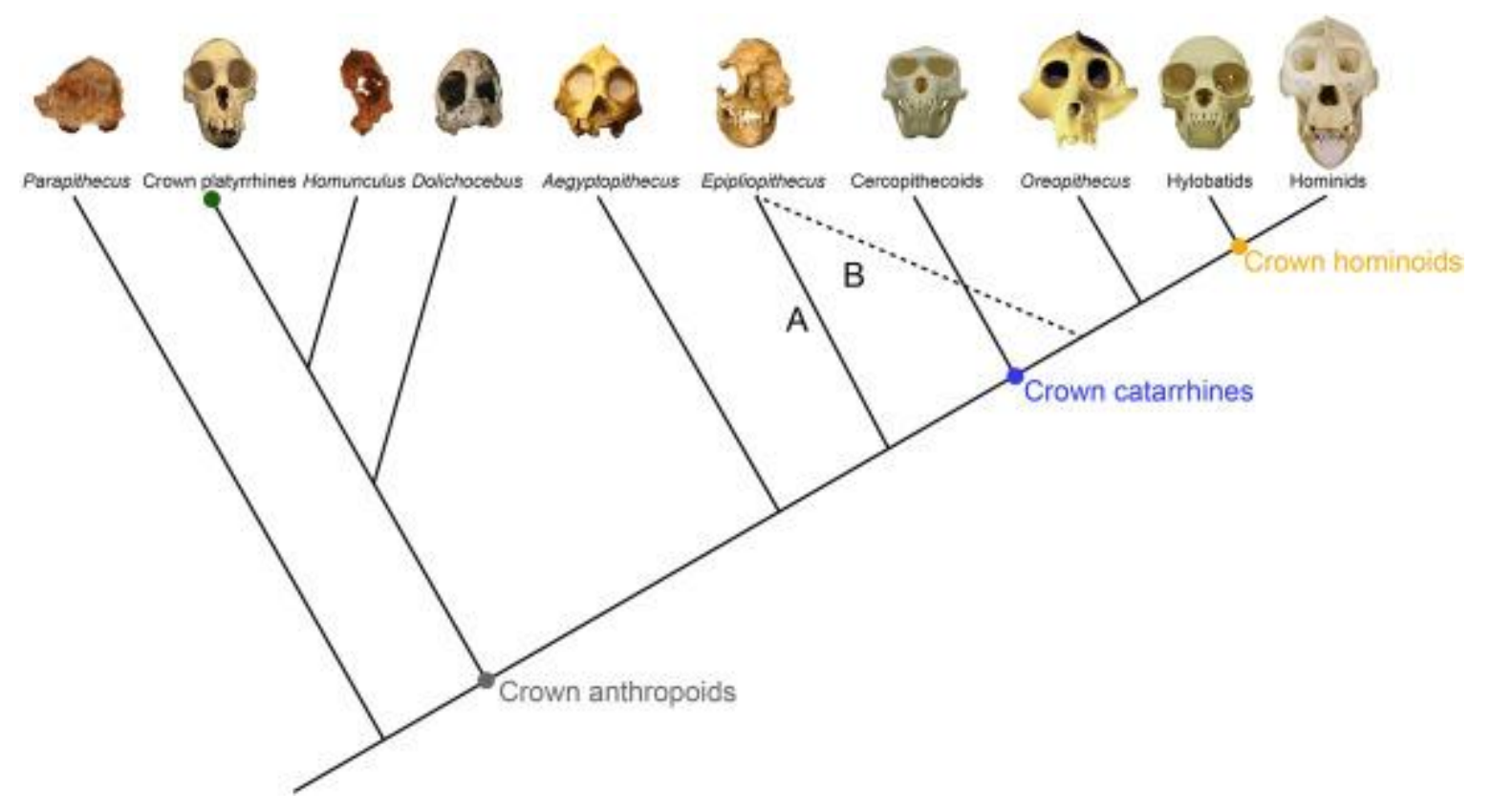


a

a Parapithecus

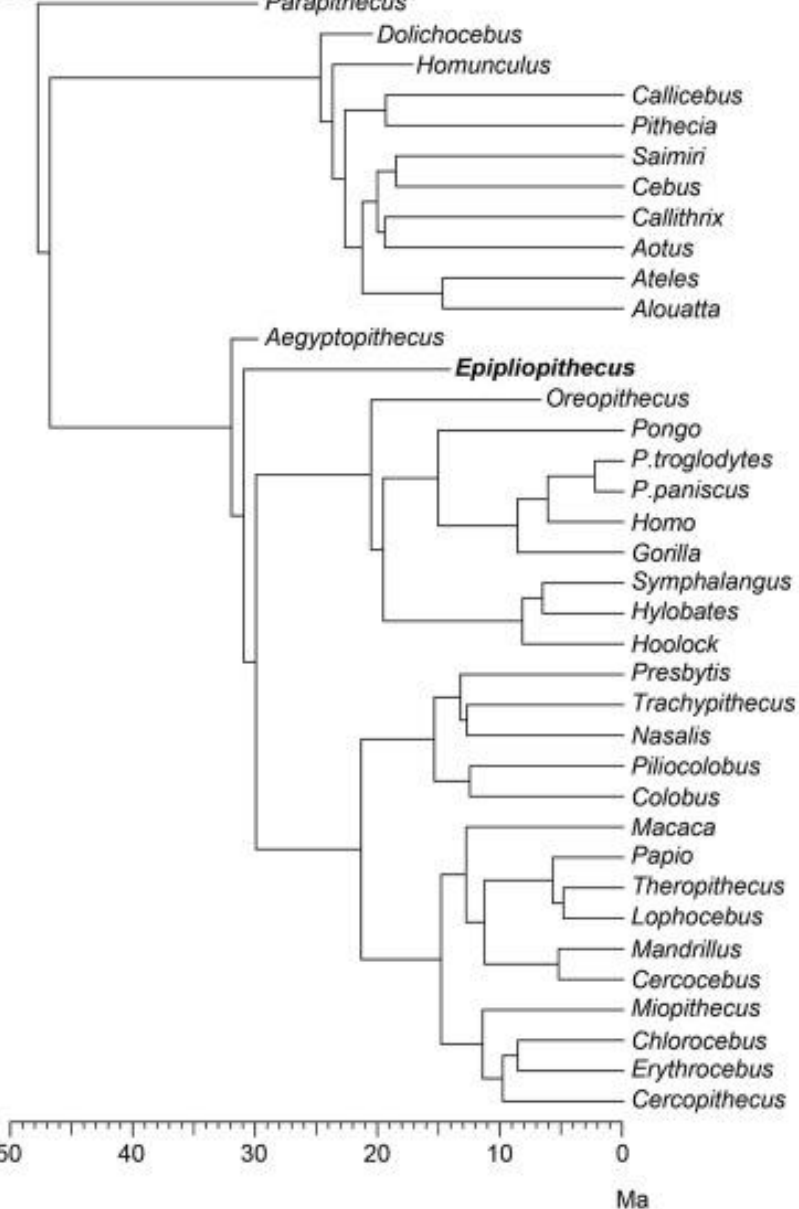

b

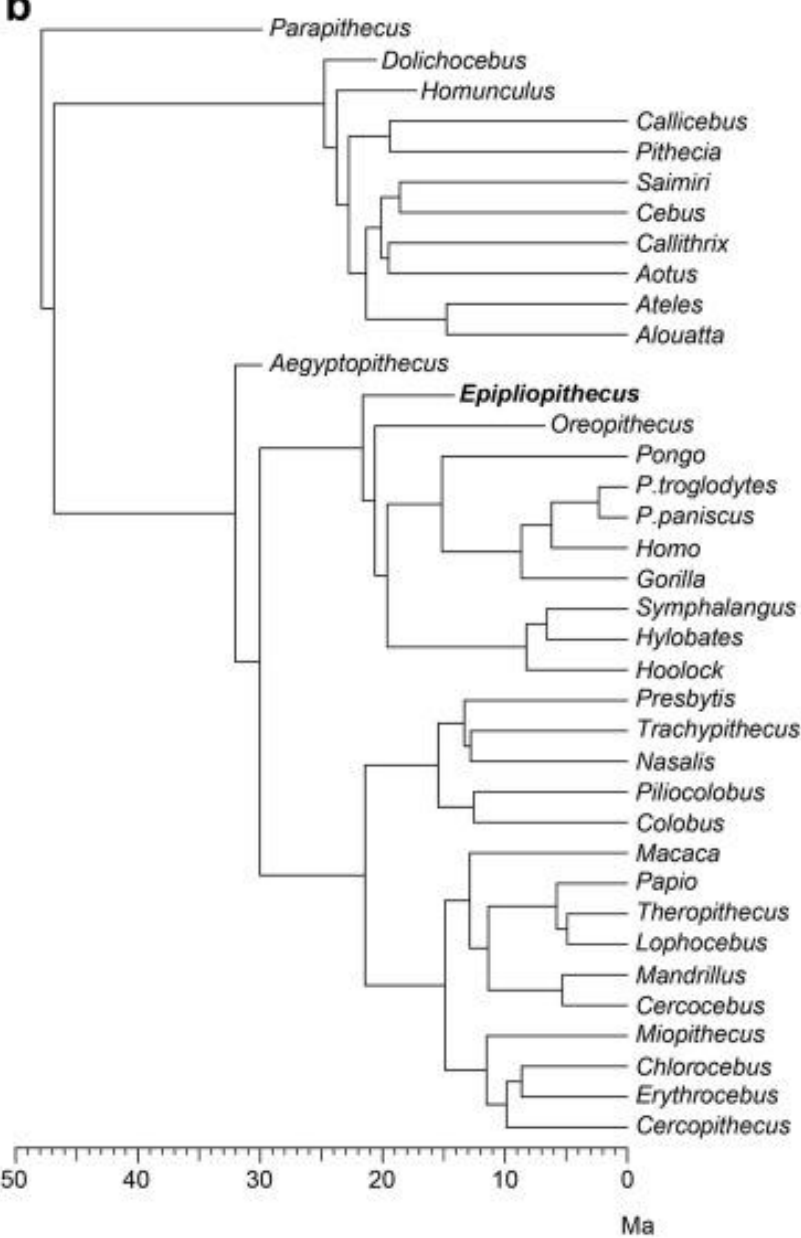




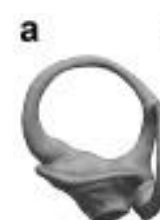

Epipliopithecus
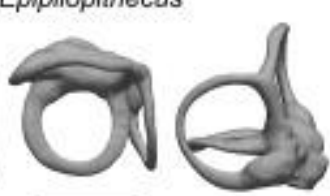

d

Parapithecus
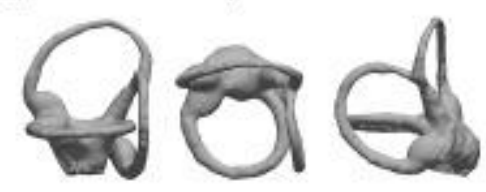

g
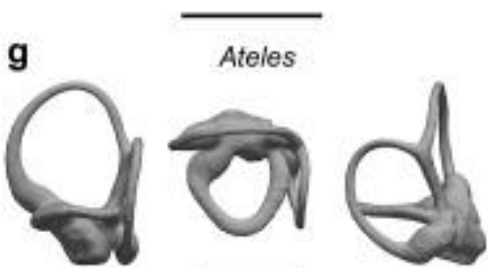

j

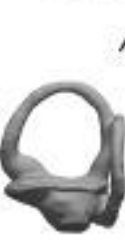

Aegyptopithecus
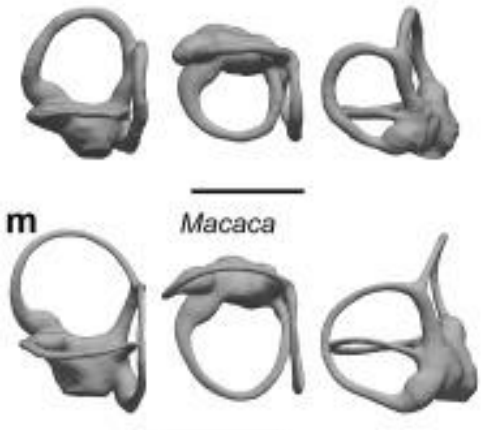

p

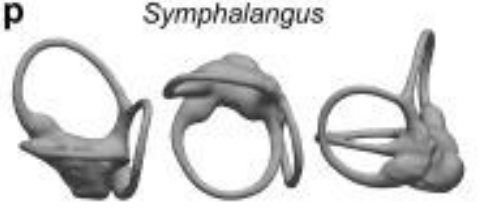

s

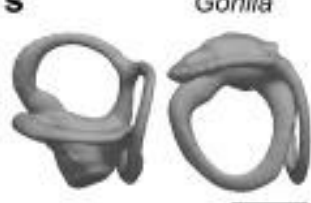

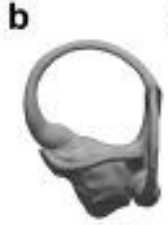

Epipliopithecus

e

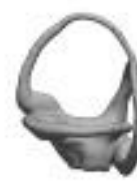

h

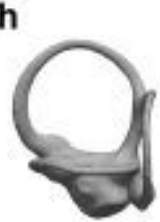

k



n

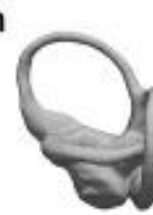

q

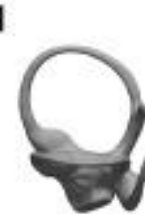

t
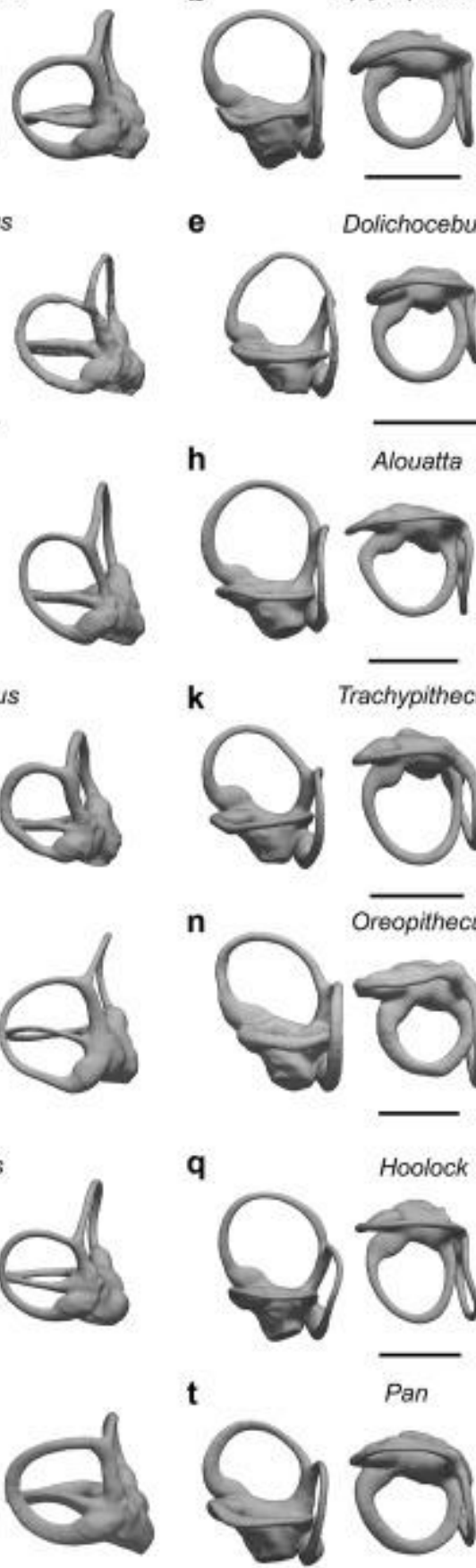

Dolichocebus
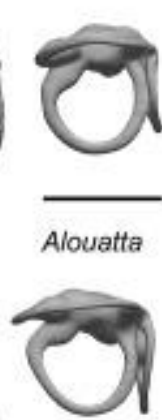

Trachypithecus
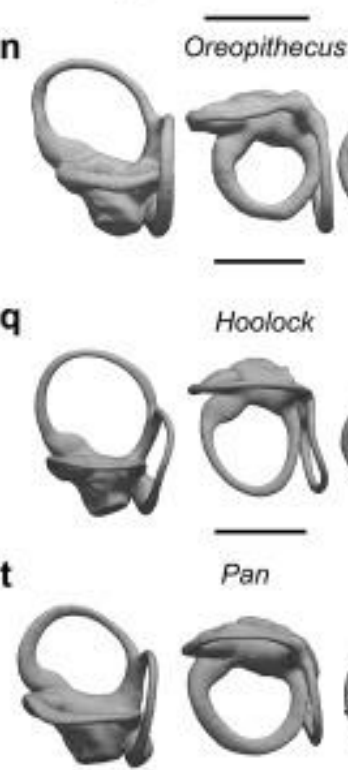
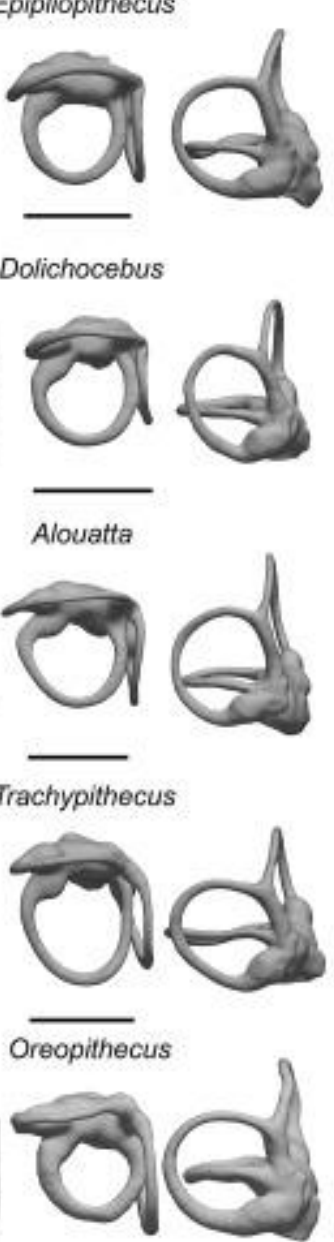

o
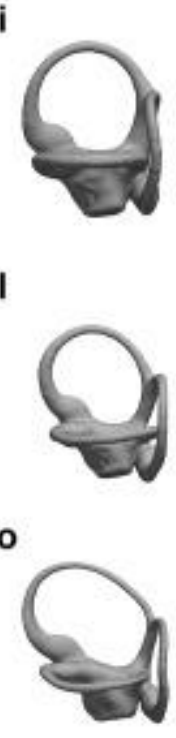

I
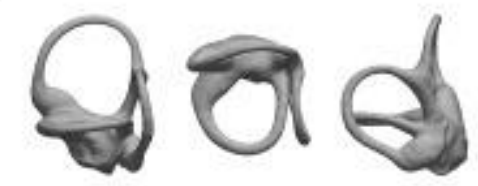

Cebus
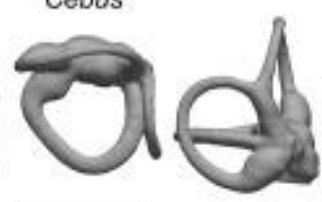

Cholorocebus

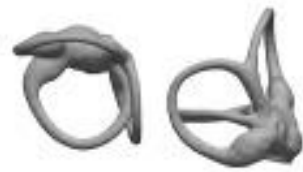

$\overline{\text { Hylobates }}$
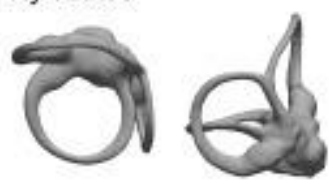

r
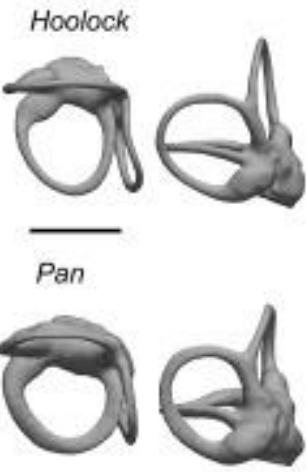



Pongo

u

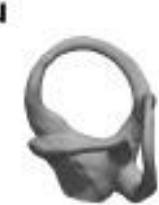






1266

In L 


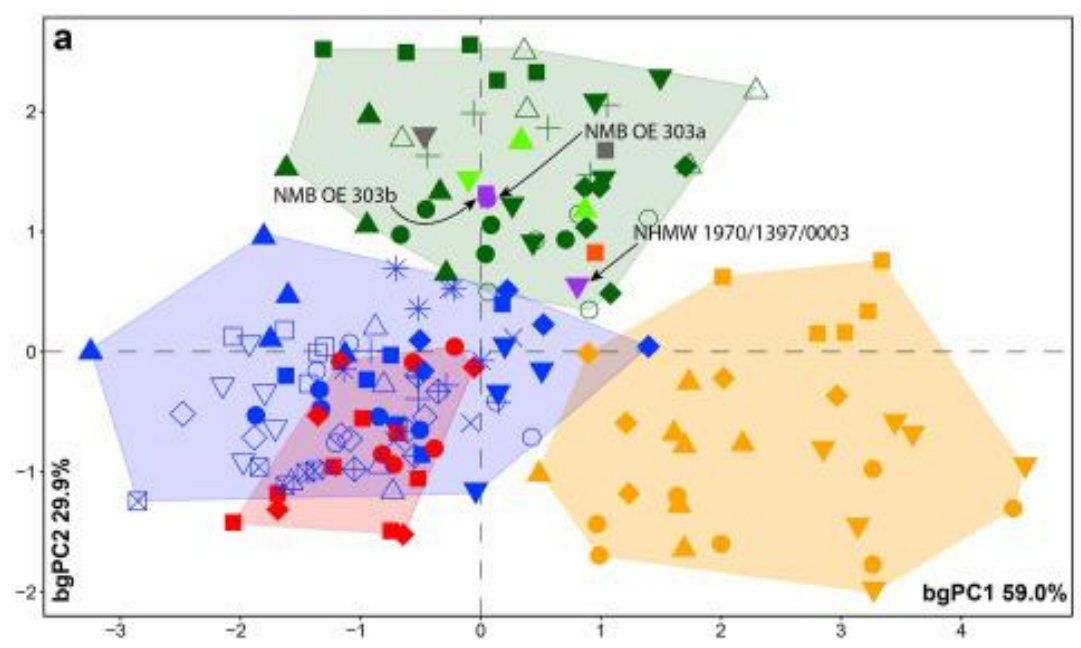

c
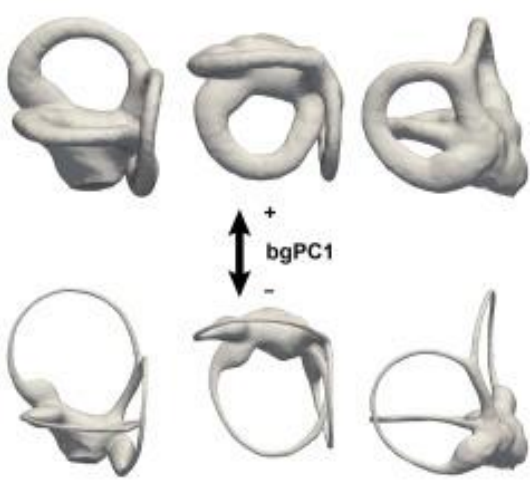

d
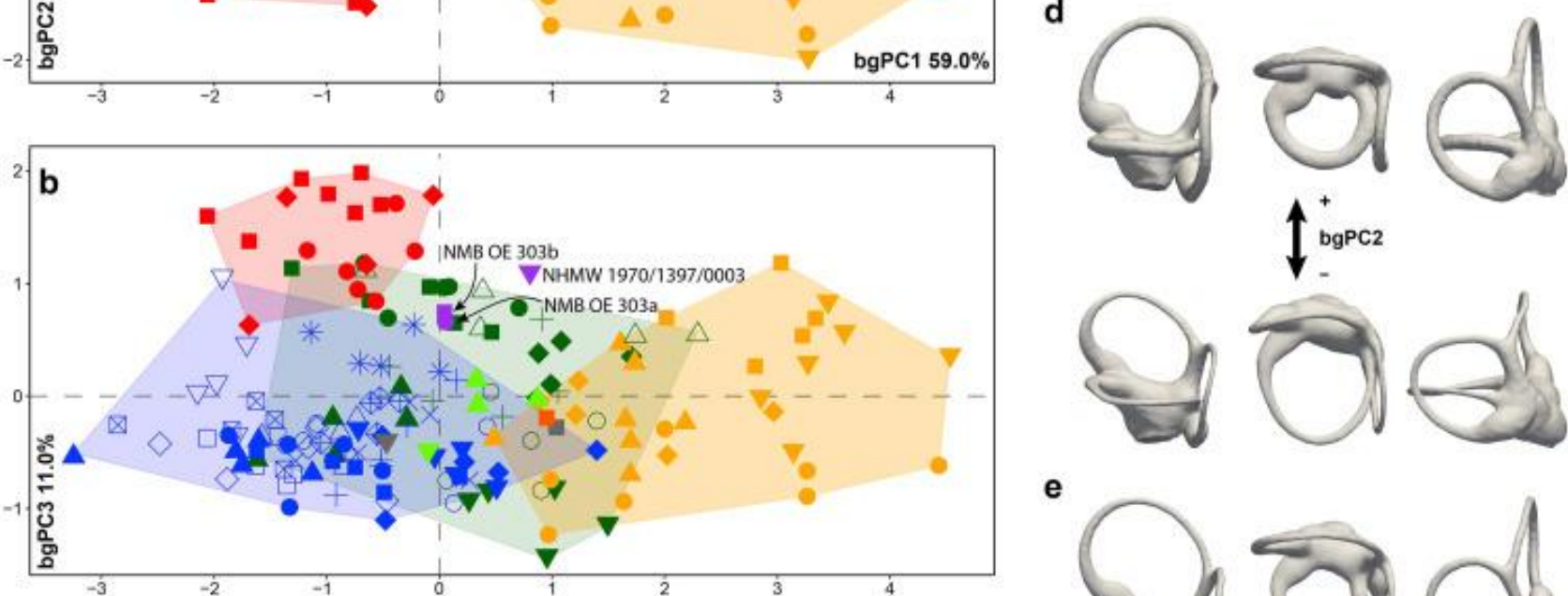

e

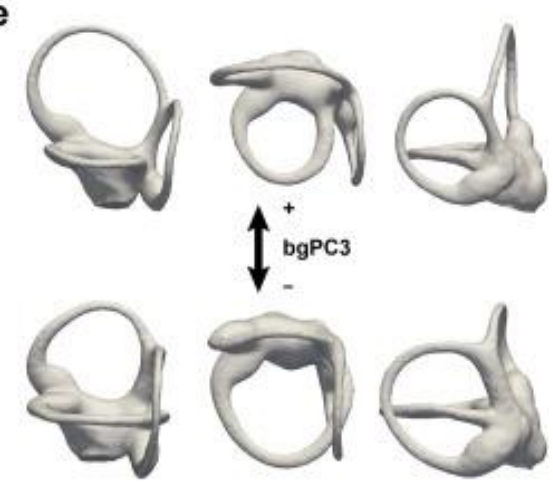

\begin{tabular}{|c|c|c|c|c|}
\hline Eteles & + Miopithecus & $\triangle$ Presbytis & Wyiobates & $\nabla$ Parapithecus \\
\hline - Alouatta & - Chiorocebus & - Cercocebus & Symphaiangus & - Aegyptopithecus \\
\hline - Cebus & $\boldsymbol{\nabla}$ Eythrocebus & $D_{\text {Papio }}$ & - Hoolock & A Homunculus \\
\hline + Saimint & Cercopithecus & O Macaca & Gonilia & Davichocebus \\
\hline$\Delta$ Aotus & $\Delta$ Colobus & $\square$ Lophocebus & $\nabla$ Pongo & Oreopithecus \\
\hline$\nabla$ Callithrix & $\nabla$ pillocolobus & $\triangle$ Mandnïus & Pan paniscus & $\nabla$ Epipliopithecus \\
\hline Calicebus & $\times$ Nasalis & * Theropithecus & A Pan trogiodytes & \\
\hline$\triangle$ Pithecia & $\oplus$ Trachypithecus & & E Homo & \\
\hline
\end{tabular}




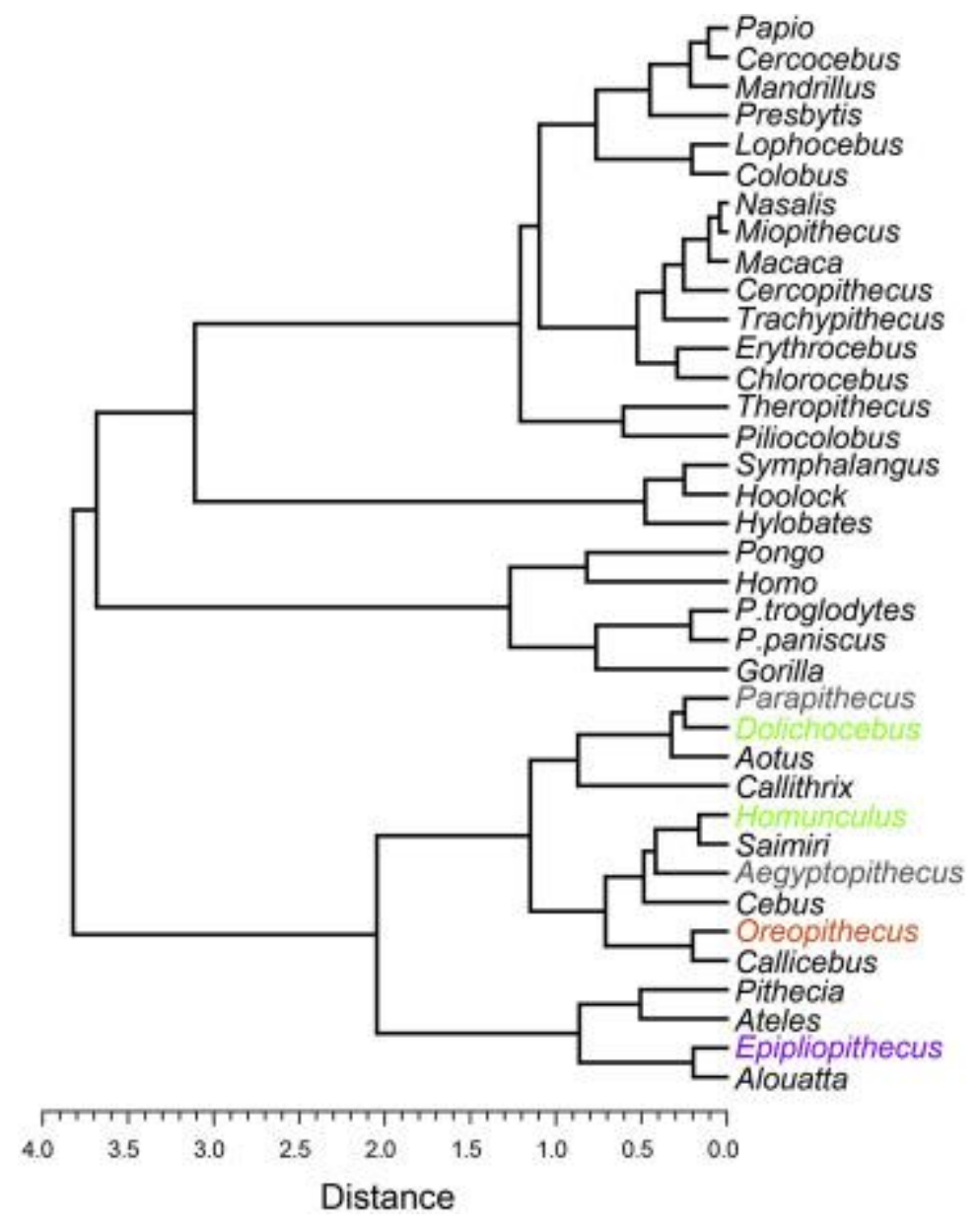




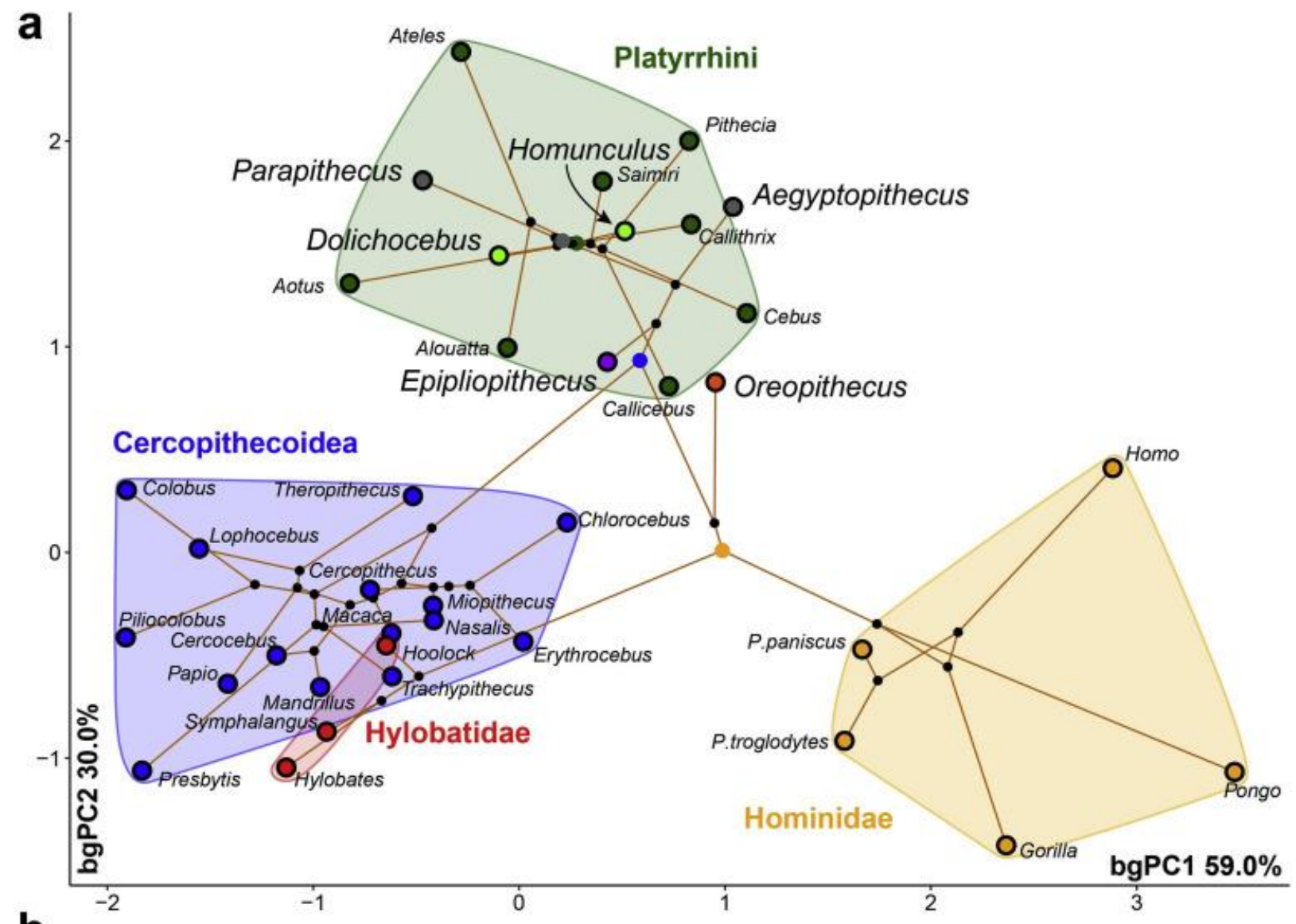

b

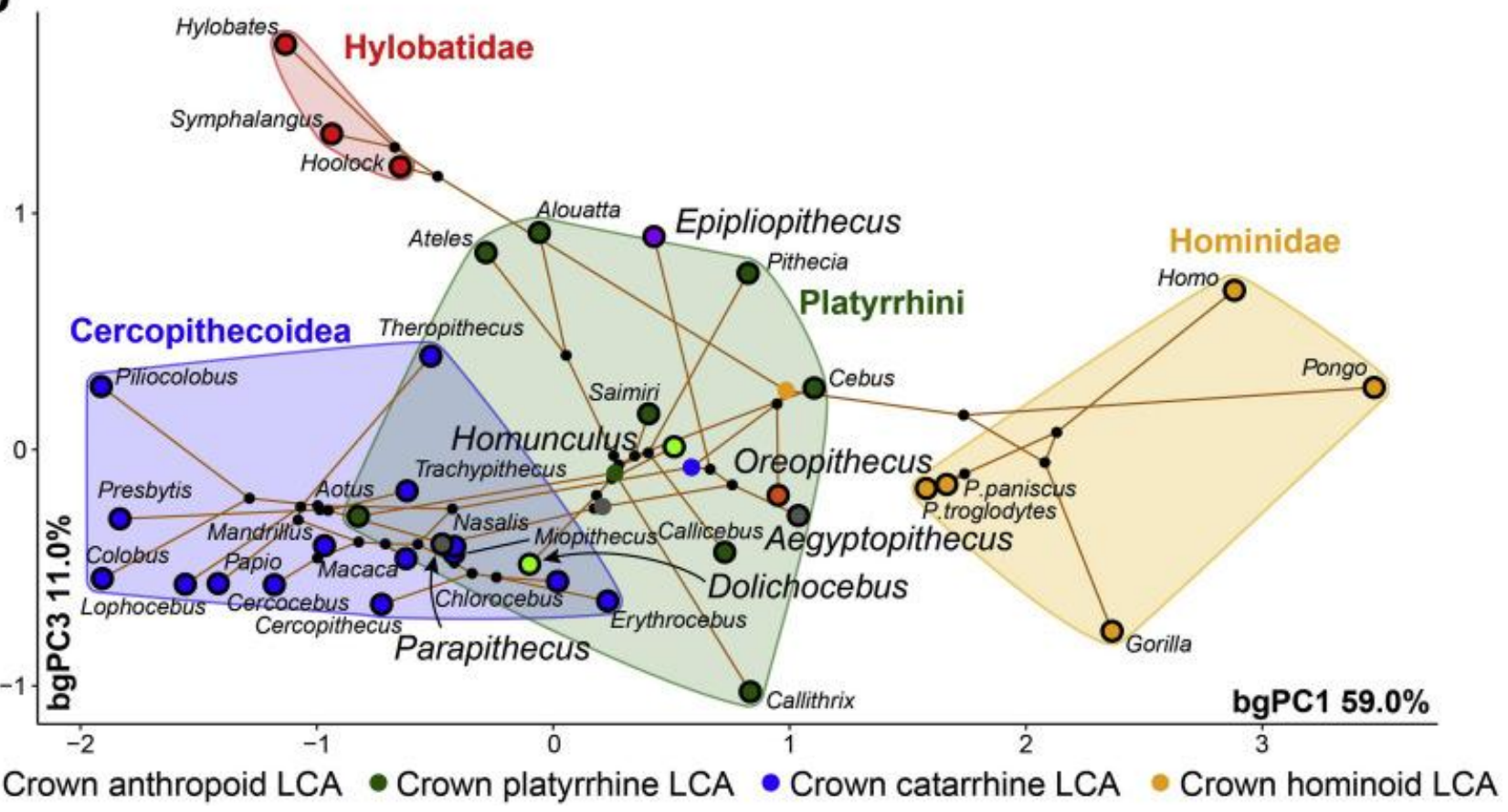


a

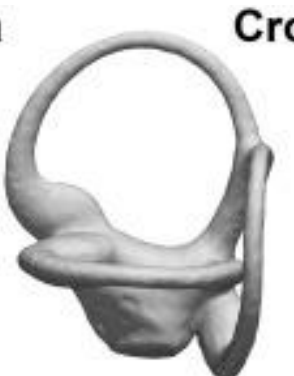

b

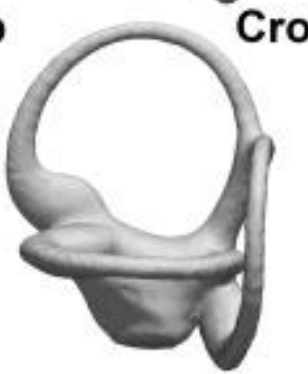

Crown platyrrhine LCA
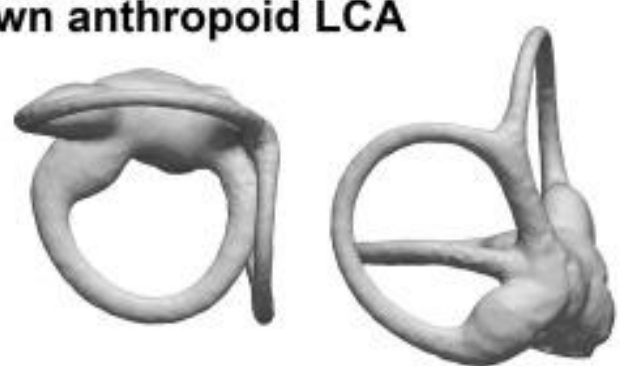

C
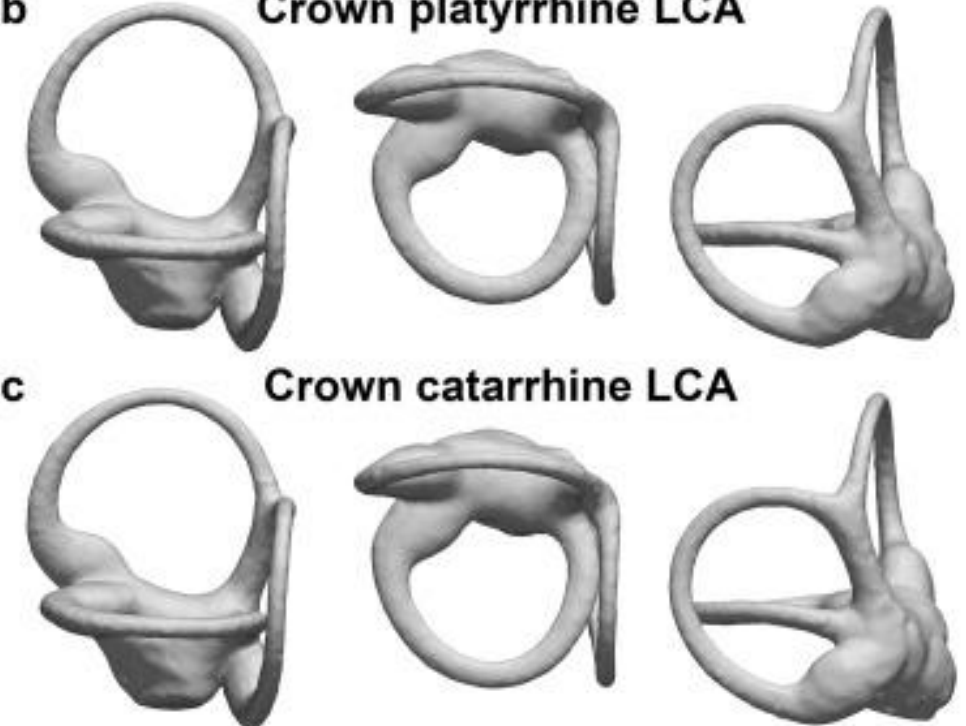

Crown catarrhine LCA
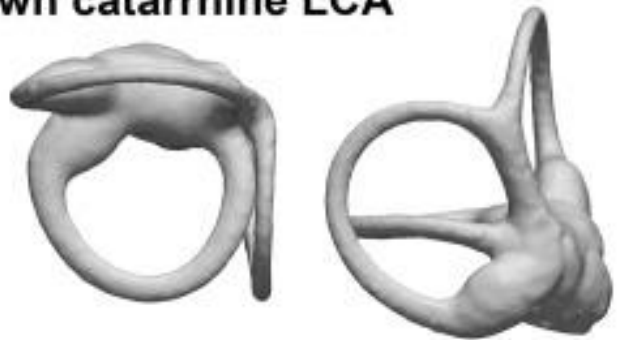

d

Crown hominoid LCA

1270
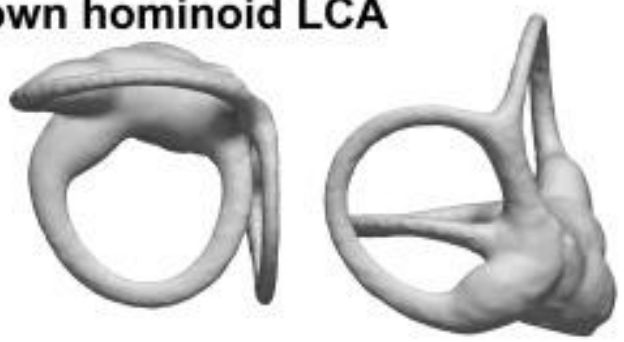
$-0.2$

0.0

0.2

0.4

0.6

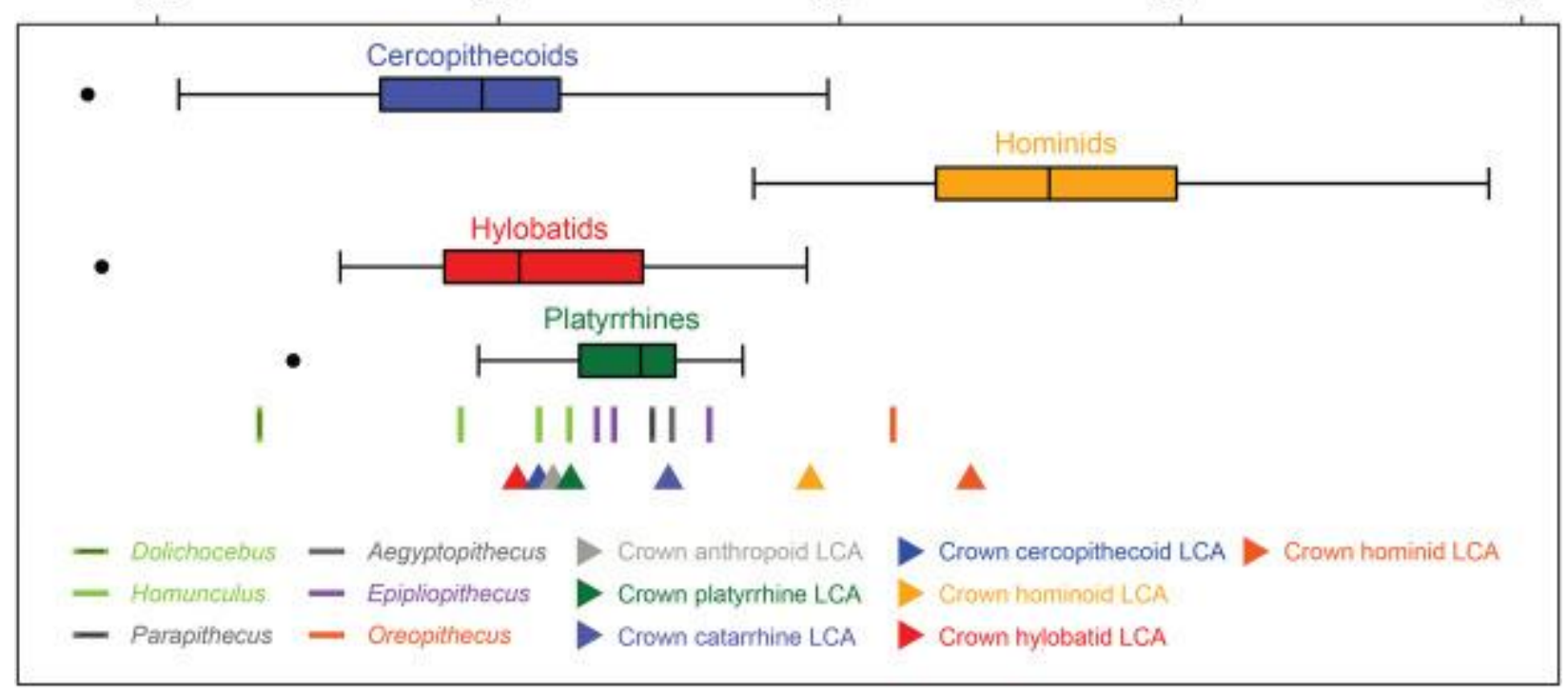

1271 
Character \#1: Size of the vestibule relative to the SCs (0) small

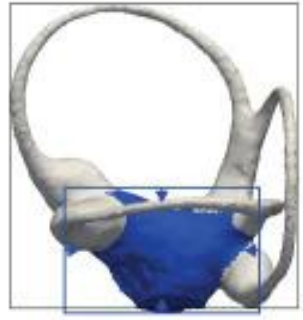

(1) large

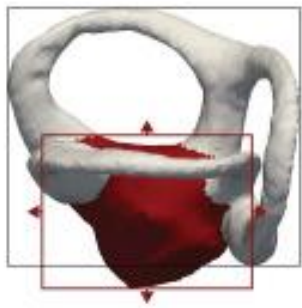

Character \#3: Shape of the anterior SC

(0) vertically compressed


Character \#5: Shape of the posterior SC

(0) vertically compressed

(1) rounded

(2) elongated superiorly
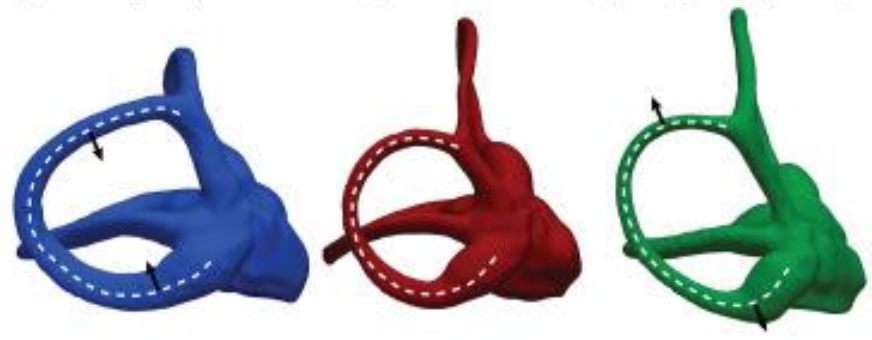

Character \#7: Length of the CC
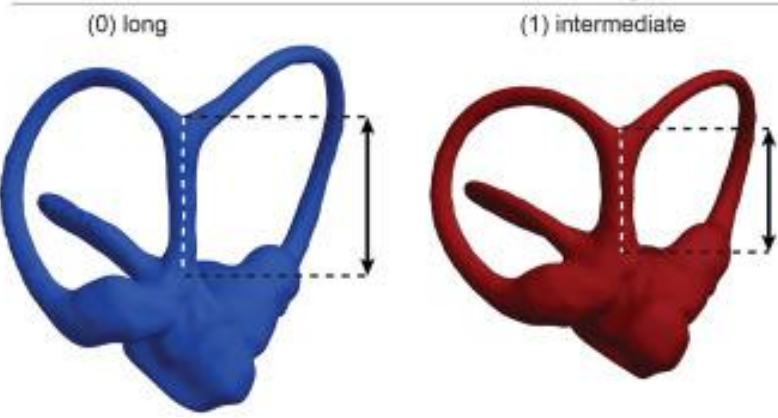

Character \#2: Robusticity of the SCs

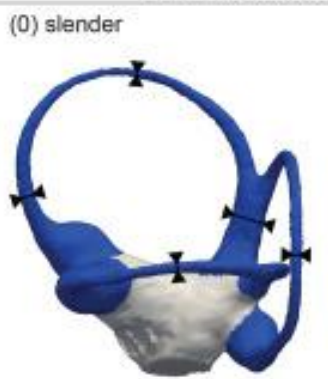

(1) stout

Character \#4: Shape of the anterior portion of the anterior SC

(0) non-anterosuperiorly projecting (1) anterosuperiorly projecting
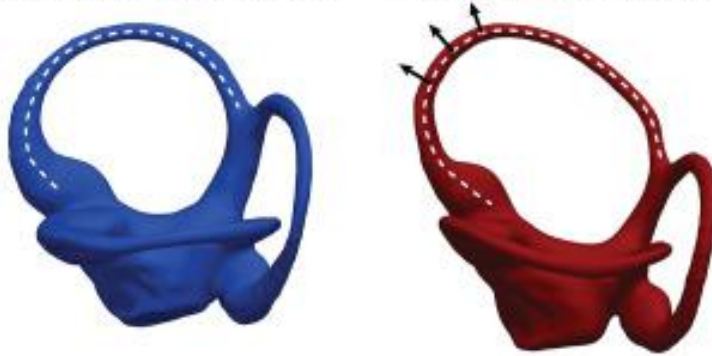

Character \#6: Shape of the lateral SC ampullary portion

(0) flat or only slightly bent superiorly (1) markedly bent superiorly
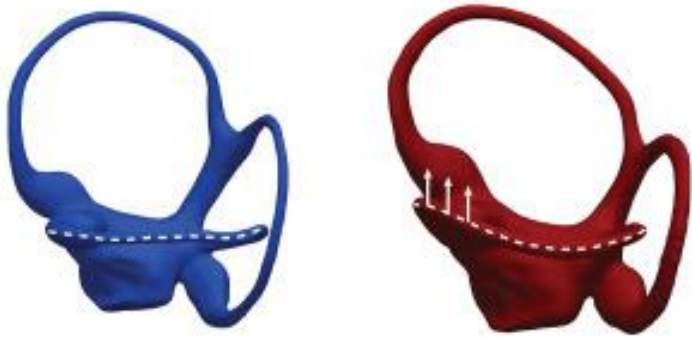

(2) short

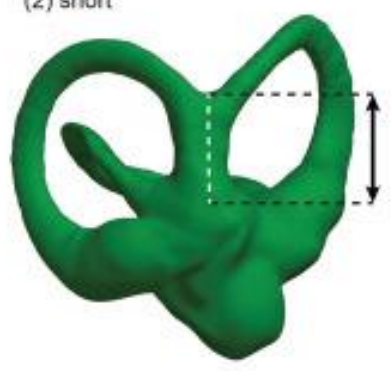




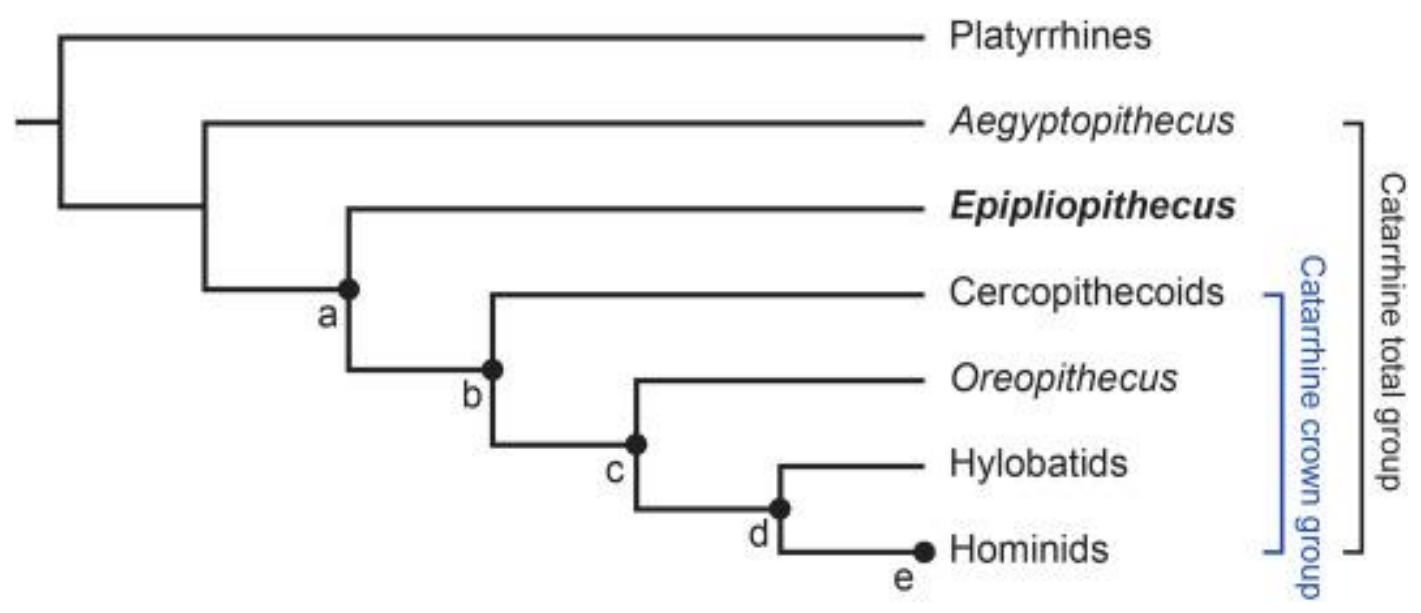

